\title{
Joris-Karl Huysmans oder Lesen als kreative Selbstinszenierung
}

Nicht nur bei Juana Borrero haben wir eindrucksvoll gesehen, dass Lesen immer auch Beschäftigung mit dem eigenen Leben bedeutet, eine kreative Auseinandersetzung, welche für dieses Leben nicht ohne Folgen bleibt. Im Lesen vergewissern wir uns der Welt und unserer selbst, vergewissern wir uns, inwieweit wir uns selbst in der Welt sehen und in welcher Form wir uns unserer selbst buchstäblich sicher sein können. Im Lesen also lesen wir immer wieder und nicht zuletzt uns selbst, unser eigenes Leben, die Alternativen zu unserem Leben und vielleicht auch das, was wir niemals werden leben können, aber doch vielleicht gelebt haben würden. Wir leiten so einen Erkenntnisvorgang ein, der in vielfachem Sinne als Selbstreflexion zu beschreiben ist und uns Auskunft gibt über das, was wir leben, gelebt haben oder leben werden, wie über all das, was wir aus welchen Gründen auch immer - niemals zu unserem Leben machen werden. Und überall dort, wo ich gerade ,leben` sagte, können Sie sich gerne an diesen Stellen auch ,lieben' denken.

Kehren wir nun vom kubanischen Modernismo zurück auf den europäischen Kontinent und in die Vorbereitungen zu einem ästhetischen Take-off der Moderne in den unterschiedlichen Modernismen, welche sich um die Jahrhundertwende überall in Europa entwickelten und verschiedenartig ausprägten!

Der französische Schriftsteller Marcel Proust, auf den wir im Verlauf unserer Vorlesung noch ausführlicher zurückkommen werden, hat im letzten Band seines Romanzyklus A la recherche du temps perdu, dem abschließenden Le temps retrouvé, diese Dimension des Lesens und deren Wichtigkeit für das Leben in ganz besonderer Weise hervorgehoben. Im Rückgriff auf einen der literarischen Höhepunkte des 20. Jahrhunderts möchte ich Ihnen gerne einen kleinen Auszug aus diesen Reflexionen präsentieren:

In Wirklichkeit ist jeder Leser dann, wenn er liest, der eigene Leser seiner selbst. Das Werk des Schriftstellers ist lediglich eine Art optisches Instrument, das er seinem Leser schenkt, um diesem zu erlauben, das zu unterscheiden, was er ohne sein Buch vielleicht niemals gesehen hätte. ${ }^{1}$

Der von Marcel Proust, einem der großen Literaten und Philosophen der Lektüre, in diesen behänden Worten in den Schlussteil seines großen Erzählzyklus einge-

1 Proust, Marcel: À la recherche du temps perdu, 4 Bde. Édition publiée sous la direction de JeanYves Tadié. Paris: Gallimard 1987 (I), 1988 (II), 1988 (III), 1989 (IV), Bd. 4, S. $489 f$. 
fügte Erzählerkommentar verdeutlicht die besondere Fähigkeit des literarischen Textes, gleichsam zu einer Art Spiegel - einem Speculum - des Lesers selbst und damit zu einem Instrument in den Händen des Lesers oder der Leserin zu werden, um sich selbst dort zu betrachten, wohin man mit eigenen Mitteln und ohne Instrument eben nicht hinschauen könnte. Das Buch, das uns die Welt zeigt, präsentiert uns zugleich auch uns selbst, lässt vor unseren Augen ein optisches Bild entstehen, in dem wir uns studieren und untersuchen, eben reflektieren können.

Insoweit enthält der literarische Text ein Lebenswissen, das ein Wissen für den Leser und die Leserin bereithält, die sich mit sich selbst beschäftigen wollen und etwas Neues, bislang Ungesehenes über sich selbst in Erfahrung zu bringen hoffen. Lesen als Selbsterkenntnis wird damit zu einer im Sinne Marcel Prousts zentralen Dimension nicht nur des Leseaktes, sondern der Literatur selbst. Auch dies verbindet auf intime Weise den Bereich des Lesens und der Lektüre mit dem der Liebe und des Liebens.

Kein Wunder also, dass manche Leser im vor ihnen aufgeschlagenen Buch ihr eigenes Schicksal zu lesen beginnen. Wir hatten dies mehrfach in Italo Calvinos Il Barone rampante sehr plastisch vor Augen geführt bekommen - bis hin zum tragischen Ende eines Banditen am Galgen, im Gleichschritt mit seinem Lesevorgang und seinem literarischen ,Helden“ alias Alter Ego. All dies war im positiven wie im negativen Sinne schon immer der Fall: Literatur kann ein Lebenswissen vermitteln, das ein Wissen über das Leben des Lesers enthält, welches sich dieser freilich auf unterschiedlichste Weise anzueignen vermag: als distanzierter Beobachter seiner selbst, als sein eigener Zerstörer oder als ein Künstler, der an seiner Selbstinszenierung beständig zu arbeiten bestrebt ist. Genau dies wollen wir uns nun bei Joris-Karl Huysmans und seinem berühmten Roman $A$ rebours näher anschauen.

Beschäftigen wir uns also mit jenem Text, der seit seinem Erscheinen im Jahre 1884 sehr rasch zur sogenannten „Bibel der Décadents“ avancierte und das wurde, was man heute schlicht ein Kultbuch zu nennen pflegt! Dies tun wir wie üblich nach einem kurzen Spaziergang durch das Leben seines Autors, denn Joris-Karl Huysmans (1848-1907) war nicht irgendwer in der literarischen Szene Frankreichs: Er war der Lieblingsschüler keines Geringeren als Emile Zola!

Charles-Marie-Georges Huysmans wurde am 5. Februar 1848 in Paris geboren. Erblich war er durchaus vorbelastet, denn von seinem Vater her entstammt er einer langen Abfolge holländischer Künstler und Maler, weshalb er später seinen Vornamen in Joris-Karl verändern sollte. Die Familie seiner Mutter hingegen war eher bescheiden: Es handelte sich um eine Dynastie von Ministerialangestellten. 
Schon 1856 starb Huysmans Vater und seine Mutter sollte sich bald wieder verheiraten. Doch Huysmans hegte einen intimen Groll gegen seinen Stiefvater. Der Junge kommt ins Internat und besucht die Institution Portus, von der er ein übermäßig strenges Andenken bewahren wird.

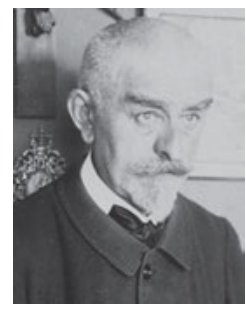

Abb. 105: Joris-Karl Huysmans, eigentlich Charles Marie Georges Huysmans (Paris, 1848 - ebenda, 1907), zu Hause, fotografiert von Dornac.

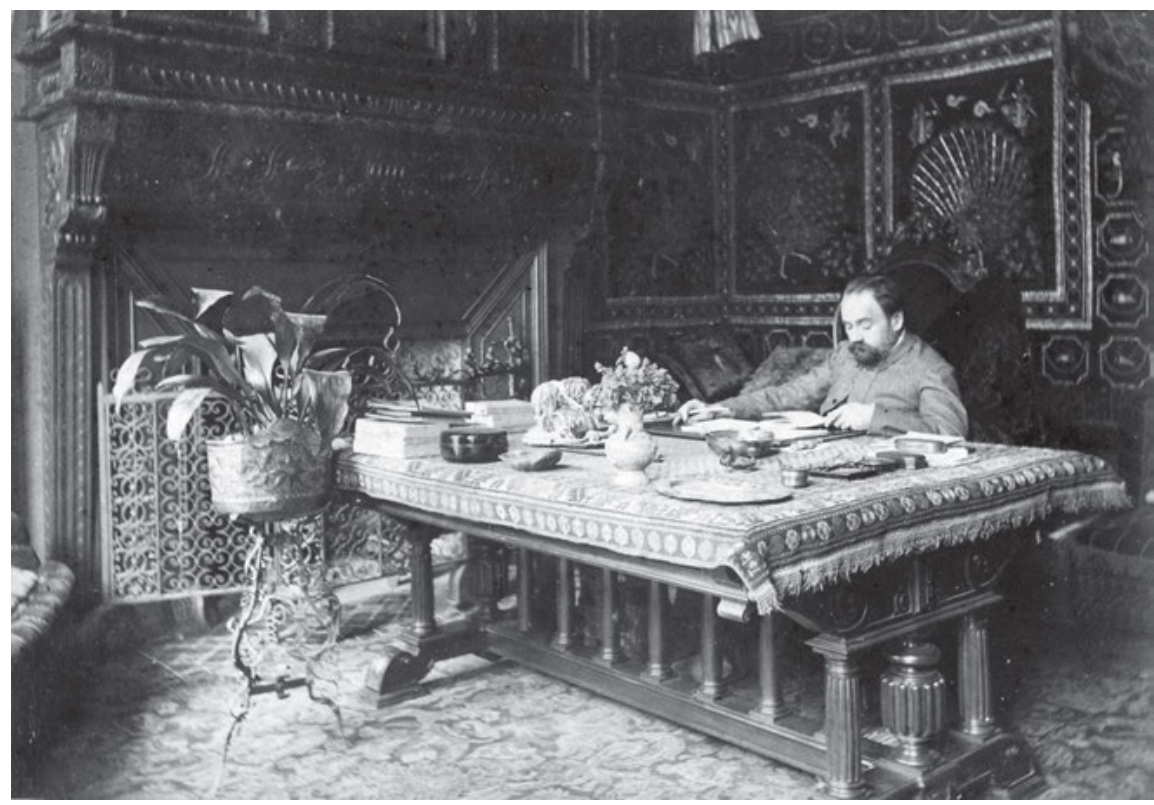

Abb. 106: Émile Zola (Paris, 1840 - ebenda, 1902) zu Hause, fotografiert von Dornac, circa 1893.

Im Jahre 1862 wechselt er zum Pariser Lycée Saint-Louis; ab 1865 erhält er eine ausschließlich durch Privatunterricht zusammengesetzte Ausbildung. Am 7. März 1866 ist er Bachelier; am 1. April tritt er eine Stelle am Innenministerium an, als employé de bureau de sixième classe zum jährlichen Sold von 1500 Francs, und scheint damit eher der familiären Tradition seiner Mutter zu folgen. 1867 besteht er sein erstes Juraexamen, doch schreibt er sich nicht erneut an der Fakultät ein. 
Denn das Leben im Quartier Latin und die Freuden der Bohème werden ihm rasch sehr vertraut. Zeitgleich zu einer Liaison mit einer drittklassigen Schauspielerin versucht er sich erstmals und recht bescheiden in literarischer Kritik. Doch Huysmans Weg führt ihn unumkehrbar weg von der Ministerialangestelltentätigkeit hin zum Künstlermilieu, in dem er nun zu überleben sucht.

1870 wird er zur Garde Nationale de la Seine eingezogen, doch erkrankt er rasch. Huysmans lernt vom Krieg nur dessen lächerlichste Seite kennen; seine Distanz und sein Abscheu gegenüber allen Formen sozialer Organisation und politischen Lebens verstärken sich immer mehr. Im Jahr 1871 arbeitet er am Kriegsministerium und erlebt die Pariser Commune von Versailles aus; ab dem Sommer desselben Jahres wohnt er wieder in Paris.

Neben seiner beruflichen Arbeit widmet sich Huysmans der Niederschrift kurzer Erzähltexte, die in unterschiedlichen Zeitschriften erscheinen. 1874 wird seine Gedichtsammlung Le drageoir à épices, das später zu Le drageoir aux épices wird, vom allmächtigen Verleger Hetzel abgelehnt. Huysmans zeigt sich nicht nur von Charles Baudelaire, sondern auch von den französischen Realisten sehr geprägt. Nach dem Tod seiner Mutter 1876 übernimmt er neben seiner üblichen Arbeit die Buchführung eines Geschäfts in der Rue de Sèvres, von dem er einen Anteil erben wird. Doch vor allem schreibt Huysmans an seinem ersten Roman, Marthe, histoire d'une fille, der in Belgien publiziert wird. Er greift darin auf Erinnerungen an die Pariser Bohème zwischen 1867 und 1870 zurück.

Mit diesem Roman beginnen seine anhaltenden Beziehungen zu den Goncourt und vor allem zu Emile Zola. 1876 schloss er sich der um letzteren versammelten Gruppe der Naturalistes an; eine Reihe von Zeitschriftenartikeln Huysmans' ergreifen Zolas Partei in der zeitgenössischen französischen Literaturszene. Zola und dessen Roman L'Assommoir erlauben ihm die Definition seiner naturalistischen Überzeugungen. Am 16. April diniert er mit Flaubert, Goncourt, Zola und dem „Groupe des Cinq“: Er ist in die höchsten Kreise des Pariser Künstlerlebens aufgestiegen.

Seine Romane siedeln sich mit Vorliebe im Milieu der Pariser Unterschicht an und beeindrucken durch ihre drastische Erzähl- und Ausdrucksweise. Erzählwerke wie Les soeurs Vatard und Sac au dos erscheinen und festigen Huysmans Ruf als ausdrucksstarker Realist und mehr noch naturaliste. In den von Zola herausgegebenen Soirées de Médan erscheint auch eine korrigierte Fassung von Sac au dos. Das Projekt der naturalistischen Zeitschrift La Comédie humaine, deren Chefredakteur Huysmans geworden wäre, scheitert jedoch. Huysmans ist mit seinen Kräften bald am Ende: 1881 muss er sich erschöpft in einer Privatklinik von seinem anstrengenden Künstlerleben erholen.

1883 erscheinen Huysmans verschiedene kunstkritische Aufsätze in der Sammlung L'Art moderne, wo sich seine ästhetischen Orientierungen ebenso 
deutlich abzeichnen wie seine Vorliebe nicht nur für die Maler des Impressionismus, sondern gerade für die Kunst von Gustave Moreau oder Odilon Redon. Den eigentlichen Wendepunkt in der Literaturauffassung unseres Autors bildet dann 1884 sein Roman A rebours, mit dem wir uns ausführlich beschäftigen werden, stellte er doch erstmals Huysmans Abkehr vom Naturalismus Zola'scher Prägung und seinen Weg in einen Ästhetizismus dar, der auch seiner Sichtweise der Lektüre eine neue Orientierung gab. Dabei gelang es Zolas Lieblingsschüler, sich entschlossen von seinem Meister abzuwenden, ohne mit ihm $\mathrm{zu}$ brechen.

1885 hält sich Huysmans im Château de Lourps in der Nähe von Provins zusammen mit seiner Lebensgefährtin Anna Meunier, die er spätestens seit 1872 kennt und um deren Gesundheit er bald in Sorge sein wird, sowie mit seinem neuen Freund Léon Bloy auf, mit dem ihn eine intensive, wenn auch eher kurzfristige literarische Beziehung verbinden wird. Der Ort besitzt eine große Anziehungskraft für den nun arrivierten französischen Romancier, der sich immer wieder nach Ruhe sehnt und zugleich stets auf der Suche nach dem Sinn seines Lebens ist. Im Folgejahr wird er hier seinen nächsten Roman En rade verfassen.

Auf seiner Sinnsuche, die ihn zeitweise auch nach Deutschland und zu Grünewalds Kreuzigung führte, welche ihm die Idee eines „naturalisme spiritualiste“ eingab, öffnet sich Huysmans immer stärker okkultistisch-spiritistischen Bewegungen und endet schließlich im Zentrum einer christlichen Frömmigkeit, die sich bereits in seinem Roman $A$ rebours deutlich abzeichnete. Lange Aufenthalte in der Abtei Saint-Martin von Ligugé, wo er sich ein Haus bauen lässt, schließen sich an. In vier Romanen wird Huysmans diese Erfahrungen verarbeiten, wobei dessen erster, Là-bas, im Jahre 1891 einen höchst erfolgreichen Auftakt zu den sich anschließenden Texten En route (1895), La Cathédrale (1898) sowie L'Oblat (1903) bildet.

Die Serie dieser zu ihrer Zeit durchaus erfolgreichen Romane konnte an den epochalen und langanhaltenden Erfolg von $A$ rebours zwar nicht anknüpfen, skizzierte aber anspielungsreich den Weg eines Schriftstellers zwischen christlicher Frömmigkeit und satanischem Okkultismus, bei dem sich unverkennbar ästhetizistische Tendenzen kunstvoll entfalteten. Nicht umsonst wählte Michel Houellebecq für seinen umstrittenen Roman Soumission als Protagonisten einen jeglicher Werte und Überzeugungen baren Literaturwissenschaftler, der über Joris-Karl Huysmans promoviert hatte. Am Ende seines Lebens zog sich der historische Huysmans in ein Pariser Benediktinerkloster zurück, wo er schließlich am 12. Mai 1907 einem langen Krebsleiden erlag. Als Schriftsteller hatte er es gleichwohl geschafft: Noch zu Lebzeiten war Huysmans in die Légion d'Honneur aufgenommen worden und wurde erster Präsident der Académie Goncourt. 
Eindeutige Zeichen eines gesellschaftlichen Erfolges, der seinem literarischen Werk zuteilwurde.

Soviel mag als erster Überblick an dieser Stelle genügen! Wir haben in diesen einführenden Abschnitten über eine Reihe von Elementen biographischer Natur gesprochen, die man sehr wohl auch im Roman $A$ rebours als autobiographische Züge an der Hauptfigur dieses Textes nachweisen kann. Huysmans Protagonist ist der Duc Floressas des Esseintes, ein wahrhaft klangvoller Name, wie wir ihn oft bei den Helden des Fin de siècle beobachten können.

Diese autobiographischen Bezüge wurden nicht durch die Forschung und die Sekundärliteratur zuerst an diesen Text herangetragen, sondern durch Huysmans selbst. Er tat dies neunzehn Jahre nach der Erstveröffentlichung von A rebours, also gleichsam aus einer Perspektive des Rückblicks aus dem Jahre 1903 auf das Jahr 1884; sozusagen aus der Erfahrung des Fin de siècle von der anderen Seite der Jahrhundertwende zurück auf eine Entwicklung, die für ihn längst Vergangenheit war. Doch es gab Grund genug hierfür, war sein Buch doch nicht - und ist es auch bis heute nicht - gänzlich zur Vergangenheit geworden, sondern behauptete sich als sein bis dato wirkungsvollstes und am meisten gelesenes Werk.

Man könnte ohne Übertreibung sagen, dass es zur Jahrhundertwende kein zweites Buch gab, das wie $A$ rebours nicht nur die Tendenzen jener Zeit seismographisch erfasst und in einer großen literarischen Figur eingefangen hätte, sondern auch eine solche Vielzahl an Imitationen und Einflüssen, an Modellen und Einfällen an spätere Autoren weitergab, so dass in gewisser Weise $A$ rebours zum Modell des Romans im Fin de siècle werden konnte. Viele der in der Folge behandelten Werke beziehen sich direkt oder indirekt auf $A$ rebours.

Wir werden beileibe nicht alles an Texten hier aufarbeiten können, was die Spuren von Huysmans bekanntestem Text enthält: Das ist schon aufgrund der Themenstellung unserer Vorlesung nicht möglich! Aber besonders leid tut mir dies bei einem Roman, der noch im selben Jahr 1884 in New York erschien und aus der Feder eines Mannes stammt, der mit Huysmans eigentlich nur sehr wenig gemein hatte: der kubanische Essayist und Revolutionär José Martí. Die Tatsache, dass A rebours schon 1884 einen Bezugstext oder im Genette'schen Sinne einen Hypotext in Übersee, bei einem hispanoamerikanischen Autor fand, mag darauf verweisen, welch große Bedeutung der französische Roman seit seinem erstmaligen Erscheinen entfaltet hatte. Die sogenannte ,Bibel der Dekadenz' war eben das: ein Lesebuch, ein Buch der vielen Lektüren gerade auch durch nachfolgende Autorinnen und Autoren.

Beschäftigen wir uns also zunächst mit dem auf das Jahr 1903 datierten Vorwort, der Préface écrite vingt ans après le roman! Hier stellte Huysmans den Roman in den Kontext seines gesamten Schaffens, versuchte allenthalben 
Entwicklungslinien aufzuzeigen und verwies auf Elemente seiner Biographie, die sich in den Seiten aus dem Jahr 1884 finden lassen. Wir haben es in diesem Vorwort also mit Huysmans als Leser seiner selbst zu tun - freilich vordergründig vor allem als Leser seiner eigenen Bücher. Es handelt sich um einen überaus wichtigen Paratext, der seit seinem ersten Erscheinen stets den Neuausgaben des Bandes beigegeben wurde; und es stellt in mehr als einer Hinsicht das künstlerische und religiöse Glaubensbekenntnis, ein wahrhaftiges Credo des französischen Autors im Angesicht seiner eigenen Schöpfung dar.

Jorge Luis Borges hat in einer wichtigen Bemerkung einmal darauf aufmerksam machen können, dass Autoren stets ihre eigenen Vorläufer schaffen, nicht also die Vorläufer ihre Nachfolger. Ein wenig besitzt auch dieses Vorwort eine derartige Funktion, verwandelt es doch den Roman $A$ rebours nachträglich in einen Haupttext, in dessen Kapiteln jeweils en germe die nachfolgenden Romane Huysmans enthalten seien. Paratextuell wird hier auf eine zentrale Bedeutung des Buches innerhalb der Intratextualität aufmerksam gemacht, freilich aus einer Kontextualisierung heraus, die zunächst einmal intertextuell bestimmt wird.

Denn von Beginn an wird $A$ rebours in einen ursprünglichen Entstehungszusammenhang gebracht, innerhalb dessen zum damaligen Zeitpunkt der Naturalismus Zola'scher Prägung noch deutlich vorherrschte. Dieser Naturalismus aber, so Huysmans 1903, sei 1884 schon erschöpft gewesen - eine etwas kühne Behauptung - und habe stets nach denselben Rezepten weitergekocht, wodurch er sich und die französische Literatur überhaupt in eine literarhistorische Sackgasse gebracht habe. Die logische Konsequenz war, nachträglich $A$ rebours zu jenem Text zu stilisieren, der aus dieser Sackgasse wieder herausgeführt habe. Das war nicht schwer darzustellen, gibt es doch gute Gründe dafür, diese Entwicklung in der Tat so zu sehen.

Damit finden wir also auf der intertextuellen Ebene - wohlgemerkt, paratextuell vermittelt - eine Frontstellung gegen den Naturalismus, zu dessen Hauptvertretern Joris-Karl Huysmans damals zurecht selbst gezählt worden war. Er gehörte zu den Soirées de Médan, dem inneren Kreis der Freunde und Schüler Emile Zolas, und galt durch eine Reihe bereits veröffentlichter Romane als einer der künftigen großen Vertreter des französischen Naturalismus.

Doch Huysmans war zwar durch den Naturalismus zu einer bekannten Größe innerhalb des literarischen Feldes Frankreichs geworden, auf die Funktion eines Schülers des großen Zola wollte er sich jedoch nicht reduzieren lassen. Wir könnten hier im Sinne von Harold Bloom ${ }^{2}$ von einer Art anxiety of influence

2 Vgl. Bloom, Harold: The Anxiety of Influence. New York: Oxford University Press 1973. 
sprechen, einem Bemühen, sich vom großen Meister loszusagen, wobei wir freilich betonen müssen, dass Huysmans den Bruch mit Zolas Ästhetik niemals als einen persönlichen Bruch mit Zola selbst inszenierte, dessen Ästhetik er zwar für tot erklärte, seine schriftstellerische Kraft und Energie er aber noch immer sehr bewunderte.

So erstaunt es auch nicht, wenn Huysmans in seiner Préface von 1903 eine Begegnung mit Zola inszenierte und zwischen diesem und sich selbst einen Dialog über ihre unterschiedlichen Positionen nach der Veröffentlichung von $A$ rebours im Jahre 1884 entwickelte. Bei dieser Gelegenheit wirft Zola dem Jüngeren vor, eine Gattung geschaffen zu haben, die sich bereits in einem einzigen Roman erschöpft habe, eine Gattung also, der keine Zukunft beschieden sei. Huysmans solle zum rechten Weg der Sittenstudie, der soziologisch fundierten Untersuchung zurückkehren, wie er sie schon in früheren Romanen erfolgreich durchgeführt habe.

Doch Huysmans war hierzu nicht bereit; und in diesem Gespräch - wie in der Préface selbst - mischen sich in die Erzählerstimme die verschiedenen Zeitebenen, insbesondere jene des Jahres 1884 (die Ebene der erzählten Zeit) und des Jahres 1903 (die Ebene der Erzählzeit). Dabei kommt Huysmans, oder der Verfasser des Vorwortes, gegen Ende seiner Préface zur folgenden Schlussfolgerung:

Ich hörte ihm zu und dachte, dass er zugleich recht hatte und falsch lag, denn er hatte recht, wenn er mich anklagte, die Grundlagen des Naturalismus zu untergraben und mir jeglichen Weg zu verbauen, und er lag falsch, weil für mich der Roman, so wie er ihn begriff, todgeweiht und von seinen Wiederholungen her verbraucht war, jeglichen Interesses bar, ob er dies nun wollte oder nicht.

Es gab so vieles, was Zola nicht verstehen konnte; zunächst einmal das Bedürfnis, das ich empfand, die Fenster zu öffnen, einem Milieu zu entfliehen, in welchem ich erstickte; dann das Begehren, das mich packte, die Vorurteile abzuschütteln, die Grenzen des Romans zu durchbrechen, Kunst hineinzubringen, Wissenschaft, Geschichte, sich mit einem Worte nicht länger dieser Form wie eines Rahmens zu bedienen, sondern ernsthaftere Arbeiten einzuführen. Ich wollte, und das frappierte mich am meisten in jener Epoche, die traditionelle Intrige, ja sogar die Leidenschaft, die Frau abschaffen, wollte den lichtvollen Pinsel auf eine einzige Figur konzentrieren, um jeden Preis etwas Neues schaffen. ${ }^{3}$

Diese Zeilen klingen noch heute wie ein Glaubensbekenntnis und zugleich eine Rechtfertigung gegenüber dem naturalistischen Lehrmeister Zola, der den Aufbruch des Jüngeren nicht verstehen konnte oder wollte. Das Neue sollte geschaf-

3 Huysmans, Joris-Karl: A rebours, Paris: Georges Crès 1922, Préface, S. xix. 
fen, die Grenzen des Romans sollten überwunden werden, Aussagen, wie sie seit Beginn der modernen Geschichte des Romans, also seit Cervantes' Don Quijote de la Mancha, ein ums andere Mal in immer wieder neuen, aber ähnlichen Formulierungen niedergeschrieben wurden. Darin lag nicht das Neue bei Huysmans, denn dergleichen hatte man schon sehr häufig gelesen und gehört.

Doch Huysmans wollte mehr, wollte mit „der Frau“ vor allem auch die intrigue amoureuse, die Liebesgeschichte selbst abschaffen, die doch in jedem noch so verschiedenartigen Roman der Naturalisten die gesamte Handlung befeuerte und vorantrieb. Der Roman sollte nicht mehr nur die Form sein, derer man sich beliebig bedienen konnte; er schien Huysmans vielmehr wie geschaffen dafür, etwa Wissenschaft und „ernsthafte Arbeiten“, die Ergebnisse unterschiedlichster Studien auf den verschiedenartigsten Gebieten vorzulegen. Dies zielte vor allem auf den wissenschaftlichen Anspruch des roman expérimental, wie ihn Zola in Rückgriff auf naturwissenschaftliche Konzeptionen von Wissen und Wiederholbarkeit formuliert hatte und wie sich der Roman auch selbst als ein Laboratorium der Gesellschaft in Szene zu setzen versuchte. „Ernsthafte Arbeiten“ und Studien hatte gerade der naturalistische Roman à la Zola in Hülle und Fülle geliefert und sich selbst als Gesellschaftslabor profiliert.

Die Abschaffung der Liebesgeschichte, der intrigue amoureuse, war also die eigentliche Stoßrichtung von Joris-Karl Huysmans neuer Ästhetik. Genau an diesem Punkte aber galt es nun, das Strickmuster der Zola'schen Ästhetik zu verändern, in der es, so Huysmans einige Seiten vorher, stets nur um die Frage des sechsten Gebotes, um Ehebruch also, gegangen war, wobei die Hauptfrage der sogenannten Sittenstudien, über die Huysmans sich nun lustig machte, stets nur gelautet hatte: tombera ou tombera pas? Mit anderen Worten: Die Frau fällt um oder fällt nicht, es kommt zum Ehebruch oder eben nicht - stets war der Ausgang der Liebesgeschichte in den Augen Huysmans im naturalistischen Erzählmodell das Entscheidende. Aber genau mit diesem uralten Befeuerungsverfahren von Literatur wollte er nun brechen.

Denn man habe Sittenstudien gefertigt, die immer nach demselben Muster verliefen, die man in ihrer gesellschaftlichen Situierung zwar verändern konnte einmal die Liebe im Adel, ein andermal die Liebe in der Arbeiterschaft -, die letztlich aber langweilig und obsessiv immer wieder auf das zentrale Thema zurückfielen. An dieser Stelle setzt Huysmans Erneuerung an, die intrigue traditionnelle, die traditionelle Handlung, das altbekannte Strickmuster des Romans, so grundlegend als irgend möglich zu verändern und dabei die Frage der Liebe möglichst vollständig aus dieser Intrige auszublenden. Dies bedeutete folglich, die Leidenschaft und die Frau, wie es hier so eindeutig wie simpel heißt, komplett aus der histoire, aus der story des Romans auszuschließen. 
Dabei wollen wir uns hier nicht zuerst um die Misogynie von des Esseintes oder Huysmans kümmern, sondern um die Ablösung der Liebe als zentralem Handlungsregister, als wichtigstem Reservoir an Handlungselementen, die jeder Autor oder jede Autorin dann mit wechselndem Erfolg in immer neuen und immer gleichen Kombinationen zusammenzustellen versuchte. Eine einzige Person, eine einzige Figur sollte dargestellt werden - und nicht wie im Naturalismus, zumindest dem Anspruch nach, eine ganze Gesellschaft; und der Rückgriff auf die Metaphorik der Malerei ist hier keineswegs zufällig, wird gerade sie für Huysmans doch zur wichtigsten Bezugskunst seines literarischen Schaffens. Wir sehen hier schon im Paratext die Grundfragen von A rebours sich abzeichnen, die für die Literaturen des fin de siécle allesamt von großer Bedeutung sein sollten und gerade die Problematik der Intertextualität (also des Gegenkanons und des literarischen Raumes), aber auch der Intermedialität (also der Beziehung $\mathrm{zu}$ anderen Medien und insbesondere Künsten) umfassen, am wenigsten freilich die Problematik der Interkulturalität in den Raum stellen. Dies war fürwahr ein gewaltiges literarisches Arbeitsprogramm, und Huysmans ging es mit seinen selbstgesteckten Zielen und seiner innovativen Programmatik freudig an.

In seinem Vorwort verwandelt Huysmans den Roman zugleich in einen Aerolithen, der gleichsam vom Himmel gefallen sein ganzes späteres Werk bereits enthalten habe, ohne jede Vorankündigung und ohne jeden Plan von seiner Seite. So verwundert es nicht, dass er die letzten Seiten der Frage nach der Gnade und nicht der Literatur widmete.

Denn was Huysmans aus der Rückschau besonders stark bewegte, war die Frage, wie es hatte sein können, dass sein Roman letztlich so viele Anklänge an den Katholizismus, an den Glauben der römisch-katholischen Lehre und mehr noch an ihre Ästhetik enthielt, wo er sich doch damals weder mit Glaubensfragen noch mit anderen religiösen Dingen auseinandergesetzt habe und seine eigentliche Konversion zum Katholizismus erst ein knappes Jahrzehnt später stattfand. In dieser Fragestellung - und dies ist häufig unterstrichen worden - zeichnet sich bereits jenseits der Gnadenlehre eine zum Teil auch ästhetizistisch untermauerte Bewegung ab, die in Frankreich den Namen des Renouveau catholique erhielt und den christlichen Glauben wieder in die Literatur einführen wollte. Auch für sie war Huysmans durchaus ein Orientierungspunkt.

Wir haben bereits gesehen, dass die Fragestellung des Katholizismus römischer Prägung nicht ganz zufällig in der Luft schwebte, war er doch eine der beiden tragenden Säulen der nicht nur gallisch-französischen, sondern vor allem lateinischen Identität in Frankreich gewesen. Daher war es nur konsequent, wenn Huysmans sich in seinem Vorwort gerade dem Deutschen Arthur 
Schopenhauer gegenüber kritisch verhielt, dem er sich lange - wie alle autoren des Fin de siècle - sehr verpflichtet gefühlt hatte, dessen Weg er aber beschritten habe, ohne zu wissen, wohin ihn dieser Weg führen würde.

An dieser Stelle finden wir, wie mir scheint, das durchaus zeittypische Element einer gallischen Identitätskonstruktion, die eigene ,lateinische‘ Wurzeln herauszustellen suchte, um die Latinität Frankreichs $\mathrm{zu}$ betonen. Es sind die Zeiten der Revue des races latines und eines Führungsanspruchs Frankreichs als Hegemonialmacht innerhalb einer lateinischen Völkergemeinschaft, die nun auch ,Latein'-Amerika wie selbstverständlich miteinbezog. Arthur Schopenhauer war aus dieser Perspektive nichts weiter als ein deutscher Quacksalber, der ein Herbarium trockener Klagen zusammengestellt habe, die ihrerseits nur wieder auf Klagen aus früheren Epochen zurückgriffen, aber keine Lösung zu skizzieren fähig gewesen seien.

In diese Lücke springt für Joris-Karl Huysmans der christliche Glaube; und genau hier findet sich auch die autobiographische Stoßrichtung seines Romans sowie mehr noch seiner paratextuellen Erläuterungen, seiner Entwicklung eines Lesemodells des Romans, das er den künftigen Leserinnen und Lesern vorschlug. Folglich erzählt Huysmans in seinem Vorwort auch die Geschichte seiner eigenen Bekehrung zum Glauben, um sie gleichsam als Anschluss an die intellektuelle wie spirituelle Entwicklung von des Esseintes zu präsentieren:

Nur Schritt für Schritt entledigte ich mich meiner Schale an Unreinheit; ich begann, an mir selbst zu zweifeln, aber ich muckte gleichwohl gegen die Artikel des Glaubens auf. Die Gegenargumente, die ich mir bildete, schienen mir unwiderstehlich zu sein; und eines schönen Morgens, als ich erwachte, hatten sie sich, ohne dass ich genau wüsste wie, einfach aufgelöst. Ich betete zum ersten Male und die Explosion geschah.

All dies erscheint jenen Leuten, die nicht an die Gnade glauben, als verrückt, während für diejenigen, die ihre Wirkung verspürten, keinerlei Erstaunen möglich ist; und wenn es denn eine Überraschung gäbe, so könnte sie lediglich für die Inkubationszeit gelten, in der man nicht sieht und nichts wahrnimmt, jene Periode des Abräumens von Schutthalden und einer Neugründung, die man nicht einmal erahnt. ${ }^{4}$

Die autobiographische Dimension, die Huysmans zwei Jahrzehnte später seinem $A$ rebours unterschiebt, ist auch in dieser Passage eindeutig zu verorten. Denn am Ende erzählt die Préface nicht allein die Geschichte des Romans und des bis dato erschienenen Gesamtwerks von Huysmans, sondern gipfelt vor allem in einer Geschichte seiner spirituellen Bekehrung. Diese Bekehrung aber wird zur eigentlichen Lebensgeschichte umstilisiert, die sich gleichsam in der frühen

4 Huysmans, Joris-Karl: A rebours, Préface, S. xxii. 
Abwendung von den Prämissen und Handlungsmustern des Naturalismus schon angedeutet habe, aber nur hatte materialisieren können, weil die göttliche Gnade hinzugetreten war.

So kam $A$ rebours wie ein eigentlich ferner, fremder Himmelskörper von ganz oben angeflogen, als Zeichen an die Adresse von Joris-Karl Huysmans, der gleichsam wie einst die Evangelisten Worte niedergeschrieben hatte, die er selber gar nicht verstand. Keinen Plan habe er gehabt, keinerlei Absicht, sich zum wahren Glauben zu bekehren und das römisch-katholische Christentum (und damit zugleich das génie du christianisme, wie wir mit Blick auf die in unserer Vorlesung ausgezogenen Traditionslinien hinzufügen könnten) anzunehmen. Und doch habe alles schon dagestanden, seien seine weiteren Romane hier Kapitel für Kapitel vorgezeichnet gewesen, habe er nur dem Vorgehen der Gnade und der Jungfrau keinen Widerstand entgegensetzen müssen, um seine wahre Bestimmung zu finden.

Wir haben es hier im Grunde mit einer literarischen Konstruktion zu tun, die sich romantechnisch oder narratologisch als eine continuation des Schlusses von $A$ rebours verstehen lässt, wobei hier gleichzeitig eine transfiguration hinzukommt. Denn aus dem Herzog des Esseintes ist nun Huysmans selbst geworden, aus dem Aufschrei der Romanfigur die befriedigte Einsicht ihres Autors, nun doch noch vom Herrn in seine Herde zurückgeholt worden zu sein. Hören wir uns diesen Schluss von A rebours also ruhig schon an, um zu wissen, wo der Roman endet und woran Huysmans hier autobiographisierend anzuknüpfen versucht:

Niedergeschlagen sank des Esseintes auf einen Stuhl. „In zwei Tagen werde ich in Paris sein, also los“, meinte er, „alles ist damit zu Ende; wie eine Sturmflut steigen die Wellen der menschlichen Mittelmäßigkeit hoch bis zum Himmel und sie werden den Zufluchtsort verschlingen, dessen Dämme ich nun gegen meinen Willen öffne. Ach! Mir fehlt es an Mut und mich packt eine Abscheu! Oh Herr, erbarme Dich dieses Christen, der an dem Ungläubigen zweifelt, welcher glauben will, erbarme Dich dieses Galeerensträflings des Lebens, der alleine und des Nachts ins Schiff steigt, unter einem Firmament, welches die tröstenden Fanale der alten Hoffnung nicht länger erhellen!“5

So schließt der Text mit einem einzigen Aufschrei seines Protagonisten. Mit diesem Aufbäumen wird zugleich deutlich, dass A Rebours in einer Notsituation endet, in der nur noch die letzte Gnade angefleht und erbeten wird, ein Flehen, das aber wie wir nun durch das Vorwort wissen - auf offene Ohren und auf Erlösung dieses ungläubigen Christen gestoßen ist. Damit werden dem Roman nachträglich Strukturen eines Bildungsromans untergeschoben, die in ihm so einfach nicht zu entde-

5 Huysmans, Joris-Karl: A rebours, S. 290. 
cken sind, obwohl sie auch nicht gänzlich fehlen. Die Entwicklung wird nachträglich vereindeutigt, zugleich christlich-religiös motiviert und vereinnahmt.

Diese Vereinnahmung sollte uns nicht davon abhalten, im Folgenden den Roman zwar vor dem hier skizzierten Hintergrund und der späten Selbstdeutung seines Autors zu lesen, ihn aber nicht darauf zu reduzieren. Denn dem französischen Schriftsteller war es darum zu tun, sich selbst in eine Wunschfigur umzustilisieren und in seinem eigenen Schreiben das Wirken der christlichen Gnade aufleuchten zu lassen. Letzteres aber war 1884 noch nicht im Roman erkennbar. Im Gegenteil, Huysmans muss sich der Tatsache bewusst gewesen sein, dass sein neuer Roman auf Ungnade werde stoßen müssen, zu deutlich war die Absetzbewegung und wohl auch das parodistische Element, das ihn intertextuell und über den literarischen Raum mit dem Naturalismus zugleich verband und von diesem abkoppelte. Mit A Rebours schuf Huysmans einen Roman, der den Naturalismus in erster Linie gegen den Strich las und diese Lektüre von Beginn an deutlich aufzeigte.

Dies wird bereits im ersten Teil sehr deutlich, denn er trägt einen Titel, der wie jener eines (naturalistischen) Paratextes klingt. Doch handelt es sich im Grunde nicht mehr um einen Paratext, sondern bereits um die Einleitung, welche für das Verständnis der sechzehn römisch durchnummerierten und nicht mit Untertiteln versehenen Kapitel unbedingt notwendig ist. Der Titel Notice macht zugleich auf den paratextuellen und textinternen Charakter des Abschnitts aufmerksam. Er bildet sozusagen eine Schwelle, die durch die spätere Hinzufügung des Vorworts von 1903 verdoppelt wurde.

Es ist klar, dass der Titel Notice sehr wohl einen Paratext suggeriert, dass zugleich aber diese Eröffnung bereits Teil der Romandiegese ist und uns fiktionale Gestalten vor Augen führt. Es handelt sich letztlich um ein naturalistisch bestimmtes, der Ästhetik Zolas noch verpflichtetes Stück Literatur, in dem zugleich die Vertrautheit und Verbundenheit mit dem Naturalismus aufscheint, durch die ungeheure Beschleunigung aber parodistisch gewendet wird. Der Titel Notice verweist diesen Teil in den Bereich, der außerhalb des eigentlichen bleibt, einen Bereich, an den sich zugleich etwas anderes, das Eigentliche anschließt, wodurch gleichzeitig eine Art Überwindung dieses naturalistisch gestalteten Auftakts deutlich wird. Daher ist gleich zu Beginn des Romans das Spiel mit dem Paratext recht doppeldeutig und aufschlussreich bezüglich der Herkunft, aber auch des weiteren Weges dieses französischen Autors.

Auf dieser ersten Seite des Romans haben wir es, ausgehend von einigen Portraits auf einem Schloss, das übrigens in Wirklichkeit existierte und das Huysmans selbst durch mehrfache Aufenthalte recht gut kannte, mit einer Familiengeschichte zu 
tun, wie eine derartige häufig zu Beginn naturalistischer Romane präsentiert wird. Huysmans zeigt in dieser Notice seine ganze Meisterschaft, mit Hilfe einiger weniger Pinselstriche und im Rückgriff auf einige wenige Details die Skizze einer Familie zu entwerfen, die unrettbar dem Verlöschen und dem Untergang geweiht ist.

Derartige Familiengeschichten sind uns selbstverständlich aus jedem besseren naturalistischen Roman Zola'scher Prägung bekannt, ist das Problem der Degenerierung innerhalb einer Familie doch ein Thema, das gerade die Naturalisten stark beschäftigte. Denn diese waren, in einer Art Radikalisierung positivistischer Standpunkte, davon überzeugt, dass die Grundfaktoren von race, milieu und moment in der Tat nach einer geradezu im Voraus berechenbaren Weise über Leben und Wirken, Verhalten und Verhältnisse einer literarischen Figur wie einer lebendigen, realen Person entscheiden würden.

So bekommen wir also im Zeitraffer ein Bild der Familie derer von des Esseintes: eine Entwicklung von den heroischen Zeiten des Feudaladels der Ilede-France bis hin zum allerletzten Spross der weitverzweigten, aber letztlich erschöpften Familie, eben Jean, Herzog Floressas des Esseintes. Mit siebzehn Jahren, wie wir wenig später erfahren, verfügte er bereits über sein Erbe, denn er verlor zunächst seine Mutter, die an Erschöpfung verstarb, dann seinen Vater, der an einer vagen Krankheit litt und bald das Zeitliche segnete. Jean sollte in der Tat der Letzte seines Geschlechts bleiben und keinen weiteren des Esseintes mehr zeugen. Das unentrinnbare Ende einer stolzen Familiengeschichte, die freilich mit diesem Spross in gewisser Weise noch einmal einen letzten Höhepunkt verzeichnen kann.

Dies gilt aber, wie wir ja schon wissen, nur für die Familie in der Literatur. Für die Familie der Literatur gilt dies nicht, denn da gab es nur wenige Figuren, die sich an Zeugungskraft mit des Esseintes messen konnten und so viele literarische Nachfahren $\mathrm{zu}$ zeugen verstanden. Im Roman liegt der Grund für des Esseintes' fehlende Zeugungskraft in einer Erschöpfung, die eintritt, weil er die unterschiedlichsten Sinne und Sinneswahrnehmungen aktiviert hat und ständig noch stärkere Reize benötigt, bevor auch diese ermatten. So genügen dem jungen Mann auch schon bald nicht mehr die üblichen Geliebten: Er verlangt nach ausgefeilteren, raffinierteren Genüssen, so dass der Adelige schließlich zu den akrobatischen Gymnastiken und Stellungsspielen jener Frauen gelangt, die ihn in die letzten Geheimnisse der fleischlichen Liebe einweihen. Doch bei Jean wird gerade das Fleisch aller Erregungen zum Trotze schwach. Eine drohende Impotenz bemächtigt sich seiner, die auch durch immer stärkere Reize nicht dauerhaft behoben werden kann. Dies war freilich voraussehbar gewesen, denn die fatale Degeneration war bereits in den ersten Sätzen des Romans aufgetaucht. 
Das naive Lesepublikum konnte also schon der ersten Seite ein naturalistisches Grundschema entnehmen, wobei nur etwas auffällig wirken mochte, dass dieses so schnell, gleichsam im Zeitraffer, abgespult wurde. Das war nicht nur die schriftstellerische Erfahrung von Huysmans, sondern auch kalte Berechnung des Literaten. Denn der Text inszeniert damit von Beginn an ein sehr ambivalentes Verhältnis zum Naturalismus, auch wenn er im Folgenden die anderen Determinanten neben der race - also das Milieu und den historischen Augenblick immer noch im Rahmen der Notice abhandelt.

Zugleich wird deutlich, dass im letzten Spross dieser zum Untergang verdammten Familie - die durch ihre Heiratspolitik letztlich geradezu absichtlich zu diesem Prozess beitrug und ihn beschleunigte - noch einmal der älteste Vorfahr sichtbar wird: La boucle est bouclée, alles fügt sich zum Kreis, der Zyklus ist abgeschlossen. Wir sind von Beginn des Romans folglich in einer Endzeitstimmung, einer an ihr Ende gelangten Geschichte, die sich nun gleichsam rituell noch einmal vor unseren Augen im letzten Zeugen dieser Familie vollzieht. Das ist zunächst naturalistisch fundiert, schert aber dann bald nach dieser Notice aus und schlägt einen ganz anderen romanesken Weg ein, den wir uns nun näher anschauen.

Zunächst aber erfahren wir noch einiges zur Entwicklung des kleinen Jean, der, wie sich das bei der noblesse gehört, von Jesuiten aufgezogen wurde, die ihm freilich den rechten Glauben nicht einzuflößen vermochten. Er interessierte sich stets für das Vergangene, etwa die toten Sprachen und insbesondere Latein, findet an den lebendigen, also den modernen Fremdsprachen mit Ausnahme des Französischen jedoch keinen Gefallen. Jean kann sich für die moderne Wissenschaft ebenso wenig begeistern wie für Mathematik, ist aber dem Ästhetischen in all seinen Formen - unter Einschluss der (ästhetisierten) Frauen - sehr zugeneigt. Die Jesuiten erkennen bald, dass ihr Zögling weder der gesamten Gesellschaft noch ihrer Gesellschaft, der Societas Iesu, von Nutzen würde sein können. Für des Esseintes könnte Verlaines berühmter Vers aus seinem Gedicht „Langueur“ gelten: Je suis l'Empire à la fin de la décadence.

Bald schon hat der junge Mann nicht nur einen Großteil seines beträchtlichen Vermögens durchgebracht, sondern auch die ihm zur Verfügung stehenden Genüsse ausgiebig gekostet. Die Frage stellt sich nun, was danach kommen soll. Des Esseintes sehnt sich nach all seinen Anstrengungen und Aktivitäten nach der Evasion, nach einer Arche, auf die er sich zurückziehen könnte. Und es ist nicht zufällig, dass wir hier schon jenes Motiv finden, das dann bei Marcel Proust eine wichtige Rolle spielen sollte und das in A Rebours eine Metaphorik der Schifffahrt und der Wellen einführt, welche wir auf der letzten Seite des Romans bereits 
bemerkt haben. Des Esseintes verkauft daher das alte Stammschloss, mit dem er nichts mehr anzufangen weiß, verkauft weitere Güter und Besitzungen und kauft im Gegenzug Staatsaktien, so dass er sich nun eine beträchtliche Summe als Rente auszahlen lassen kann und überdies eine gehörige Stange Geld erhält, um sich irgendwo neu niederzulassen und einzurichten. Er wird diese Summe dringend benötigen ...

Bald ist auch ein Haus etwas außerhalb von Fontenay-aux-Roses gefunden, das neben seiner Straßenbahn auch über einen kleinen Bahnhof verfügt, wodurch der junge Adlige nach Wunsch von seinem Rückzugsort recht rasch wieder zurück in die Hauptstadt Paris gelangen kann. Der Rückzug ist also nicht notwendigerweise auf Dauer gestellt, doch sind die Reisen zunächst einmal innerhalb des Hauses selbst geplant. Dies lässt sich schon am Mobiliar, insbesondere an der Schiffskabine, die sein Speisezimmer bildet, sehr leicht erkennen.

Am Ende der äußerst klug konzipierten Notice zieht sich, als das neue Haus fertiggestellt ist, des Esseintes plötzlich und ohne Vorwarnung, ja ohne eine Adresse zu hinterlassen, aus dem ihn anödenden Pariser Leben zurück auf seine kleine Besitzung, die er sorgfältig abgeschottet hat. Es ist ihm gelungen, eine kleine Welt für sich zu erschaffen. Bis hierher würde noch alles ins naturalistische Schema passen, bis hierher könnte man den Roman Zola'scher Prägung schon im Geiste ablaufen sehen, - mit den zunehmenden Schwierigkeiten des Alterns, den sich aufstauenden finanziellen Problemen und so vielem mehr noch wäre der Roman naturalistisch zu meistern gewesen.

Doch Huysmans steigt an dieser Stelle im ersten Kapitel resolut aus und bedient sich - ohne auf Elemente des Naturalismus zu verzichten - anderer ästhetischer Mittel und Verfahren, um dem zeitgenössischen französischen Roman neue Wege zu bahnen. Doch scheint mir wichtig, in dieser Notice beides zu sehen: die Herkunft aus dem Naturalismus mit ihrer Verankerung in der entsprechenden Ästhetik einerseits und die parodistische Beziehung zu dieser naturalistischen Ästhetik und diesem Romanschema andererseits, dem sich Huysmans in der Folge entziehen sollte. Auch in dieser Hinsicht markiert die Notice nicht nur paratextuell, sondern vor allem romanästhetisch eine Schwelle, über die Huysmans nicht wieder zurück in die Gefilde des Naturalismus treten wollte. Die Entscheidung war getroffen: Leinen los!

Das erste Kapitel war ein Kapitel des Übergangs und der Installation von des Esseintes in seinem neuen Domizil. Er ist mit Einrichtungen nicht unerfahren, hatte er doch einst ein boudoir rose besessen, das ihm zur Verführung der Mädchen diente, die von den vielen Spiegeln ganz verzaubert waren und sich 
deshalb darum rissen, sich in diesem rosafarbenen Zimmer in den Spiegeln selbst porträtieren zu dürfen. Die Ansprüche des jungen Mannes an Mobiliar, Einrichtung, Abstimmung aller Bereiche können kaum höher gedacht werden. Und der Einfluss dieser literarischen Intérieurs aus Huysmans' Feder auf Texte anderer Schriftsteller`innen war gewaltig.

Dies macht gleich im ersten Kapitel eine recht hübsch gestaltete Szene deutlich, die wir uns - auch wenn sie literarisch nicht so ergiebig ist - etwas anschauen sollten, zeigt sie uns doch explizit jenen Typus Mensch, mit dem wir uns noch auseinandersetzen müssen. Denn des Esseintes ist nicht nur ein Nachfahre der großen Familie von Feudalherren, sondern auch von jenem mal $d u$ siècle angesteckt, das schon die Helden eines Chateaubriand während der letzten Jahrhundertwende infiziert hatte und das wir gut kennen: Jenem ennui, der Geißel und Produktivkraft der Romantiker war. Auch ihn hat jener spleen angesteckt, von dem Charles Baudelaire, jener Dichter, den des Esseintes wirklich uneingeschränkt bewundert und vergöttert, berichtete. So lässt sich gleich $\mathrm{zu}$ Beginn eine literarische Genealogie ausmachen, ein literarischer Raum, auf den wir noch zurückkommen werden. Zweifellos aber lässt sich in A rebours vor allem eine Abfolge kultureller Befindlichkeiten und Produktivkräfte aufzeigen, die uns vom ennui der Romantik über den spleen der Jahrhundertmitte bis hin zur Figur des dandy führt, dessen große finisekulare Verkörperung fraglos des Esseintes ist. Hören wir sein Evangelium!

\footnotetext{
Er hatte schließlich einen hohen Saal vorbereiten lassen, welcher für den Empfang seiner Lieferanten vorgesehen war; sie kamen herein, setzten sich nebeneinander ins Chorgestühl einer Kirche, und sodann stieg er auf eine hohe Kanzel und hielt seine Predigt über das Dandytum, wobei er seine Stiefellieferanten und Schneider beschwor, sich auf die absoluteste Weise an seine kurzen Befehle bezüglich des Schnittes zu halten, wonach er ihnen mit einer finanziellen Exkommunizierung drohte für den Fall, dass sie nicht buchstabengetreu seine Instruktionen in seinen Erlassen und Bullen befolgten. ${ }^{6}$
}

Sie beginnen nun zu erahnen, warum man angesichts der hohepriesterlichen Inszenierung und der Rede von Bullen und Erlassen schnell dabei war, diesen Roman als die „Bibel der décadents“ zu bezeichnen. Die Szene ist recht aufschlussreich, wird hier Dandytum doch zum einen vor dem Hintergrund des Reichtums gegen die verschiedenen Handwerker, die all dies leisten mussten, ins Feld geschickt und damit mit Geld und Arbeit, die ja geleistet werden musste, in Beziehung gesetzt; zum anderen erscheint es bereits hier in der

6 Huysmans, Joris-Karl: A rebours, S. 15. 
ästhetisierenden Verkleidung der Kirche, freilich gänzlich ihrer religiösen Funktion entkleidet.

So tritt an die Stelle der Bergpredigt die Dandypredigt, an die Stelle der päpstlichen Bullen die Aufforderung zur absoluten Befolgung aller Vorschriften, um die Entwürfe des Dandys nicht durch die stets fehlerbelastete Ausführung mit der niedrigen Realität aufs Schwerste kollidieren zu lassen. Der Dandy war innerhalb einer entsakralisierten und am Mammon orientierten Gesellschaft zu einer Art Ersatzpapst geworden, welcher die reine Lehre des Ästhetischen predigte.

Ästhetik wird damit zu einer Art Religionsersatz, eine für die weitere Entwicklung nicht nur des Romans, sondern des Fin de siècle insgesamt überaus aufschluss- und erkenntnisreiche Problematik. Dieser Religionsersatz ist freilich nur für jene zugänglich, die Stendhal schon die happy few genannt hatte, eine kleine gesellschaftliche Gruppe, welche sich selbst für die Elite hält. Nicht zuletzt damit sind etwa auch die ständigen Ausfälle von des Esseintes begründet, der sich noch in Paris über die Physiognomien der Bürger erregt und unter ihnen förmlich gelitten hatte. Nun endlich findet er die Möglichkeit, sich von alledem zu trennen und das Unästhetische aus einem Leben zu verbannen.

Die Spitze zielt dabei gegen ein am Geld orientiertes Bürgertum, für das kulturelle Werte, Literatur und Kunst völlig in den Hintergrund gerückt waren nicht weniger als die Religion selbst, die innerhalb einer säkularisierten Gesellschaft längst zur Privatsache und Angelegenheit zweiter Ordnung degradiert worden war. Gesellschaftliche Modernisierung ging einher mit einer Säkularisierung und einem Verlust transzendenter Werte, gegen den nun der Versuch der Errichtung eines neuen, ästhetischen Wertekanons unternommen wird. An die Stelle der kruden Realität naturalistisch geschilderter Unterschichtmilieus trat nicht erst seit dem Fin de siècle die Kunst; doch tat sie dies gegen Ende des Jahrhunderts in deutlich verstärktem Maße. Daher ist die von des Esseintes inszenierte Form des sermon sicherlich keine ungeeignete, um diese Problematik auch in A rebours nicht nur literarästhetisch aufscheinen und erstrahlen zu lassen.

Halten wir noch ein weiteres, nicht allein für Huysmans' Roman wichtiges Element fest! Es ist die Betonung des Innenraumes, der im Fin de siècle als raffiniertes Intérieur überhaupt eine ganz ausgezeichnete Stellung einnimmt. Denn der Weg von des Esseintes ist im Verlauf des Romans fast ausschließlich einer zum Innenraum, was freilich nicht mit einem Weg zur Innerlichkeit gleichgesetzt werden darf. Des Esseintes schließt sich förmlich in seinem Hause ein, beschränkt die Kunst unter Abwehr des Außenraumes auf das Innere, gestaltet aber umso mehr dieses Innere, um es vom Außen, von der am Nutzwert orientierten Geschäftswelt 
der Bourgeoisie abgrenzen zu können. Das fin de siécle ist - nicht nur im Bereich der Literatur - immer wieder eine Epoche des Innenraumes, des Intérieur, das abgrenzen und ausgrenzen, zugleich aber auch eine andere, eine Gegenwelt zur bourgeoisen Warenwelt erzeugen will.

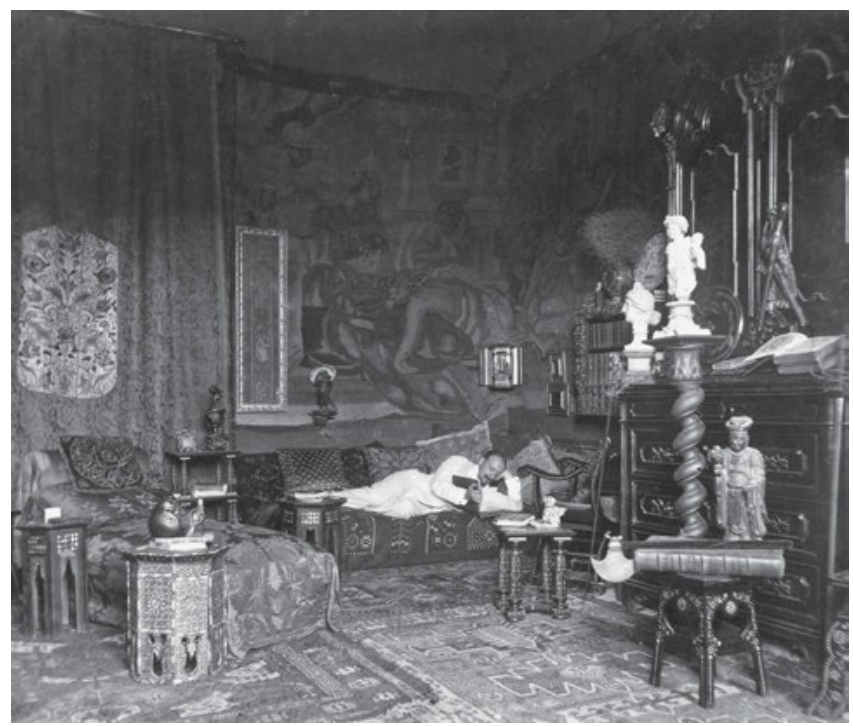

Abb. 107: Die Epoche des Innenraumes: Gabriele D’Annunzio im Atelier seiner Villa „Mammarella“ in Francavilla, Italien, 1895.

Diese Innenräume sind zugleich auch ein Bereich, in dem sich verschiedene Welten, verschiedene Künste, verschiedene Erfahrungen und Empfindungen, verschiedene sensations und Sinneswahrnehmungen überlappen, überlagern, miteinander in Kontakt treten, gemeinsam ihre Wirkungen potenzieren und eine Welt künstlerischer Synästhesien begründen, welche zweifellos die Künstlichkeit mit der künstlerischen Gestaltung zu verbinden trachtet. Synästhesie heißt zugleich, die Grenzen zwischen den verschiedenen Künsten zu überbrücken, ja zu durchbrechen, um dadurch neue Kunstwerke, ja Gesamtkunstwerke zu schaffen. Auf Richard Wagners spätromantischen Traum vom Gesamtkunstwerk waren wir bereits an anderer Stelle gestoßen; er beeinflusste nicht umsonst gerade wegen dieser intermedialen Konzeption das europäische Fin de siècle zutiefst.

Auch des Esseintes versucht von Beginn an, schon bei den Innenräumen die einzelnen Sinneswahrnehmungen aufeinander abzustimmen und aufeinander 
$\mathrm{zu}$ beziehen, ein Zusammenwirken von Farben und Musik, von Literatur und Bild, von Düften, Edelsteinen, Blumen und Blüten zu erzielen, das durch die Komposition völlig neue, originelle Effekte zeitigt. Gerade die Literatur - des Esseintes widmet sich besonders der nachantiken lateinischen Literatur - wird schon von der Gestaltung der für sie bestimmten Regale her auf diese synästhetischen Zusammen-Wirkungen eingestellt, wird eingebaut in ein Gesamtkunstwerk des Innenraumes, in dem sie kraft Lektüre einen weiteren, großartig gestalteten Innenraum schafft.

Eine besondere Funktion und Bedeutung aber kommt einer kleinen Erfindung von des Esseintes zu, die im vierten Kapitel erscheint und die vom Dandy als orgue à bouche bezeichnet wird. Sie bringt im Innenraum des Mundes die verschiedensten Sinneswahrnehmungen miteinander in Verbindung und erzeugt jene überwältigende Erfahrung, jenes überwältigende sinnliche Erleben, das im Herzen jeglicher Ästhetik des Fin de siècle steht. Wir werden uns in einer anderen Vorlesung ausführlicher damit beschäftigen ...

Es gibt im Roman eine Vielzahl weiterer, eher skurriler Elemente, die des Esseintes' Leben in Einsamkeit und Abgeschiedenheit punktieren: Da wäre etwa jenes Aquarium, das vor ein Fenster gerückt ist, so dass nur durch das Wasser gefiltertes Licht in den Raum dringen kann. Das Wasser ist gefärbt, um die Lichtwirkungen noch weiter nuancieren $\mathrm{zu}$ können. Sie fürchten jetzt um das Leben der Fische? Keine Angst! Den Fischen bekommt es, weil sie eine Aufziehmechanik besitzen, die sich nicht daran stört, verheddern sie sich doch ohnehin in den künstlichen Pflanzen, die ebenso wenig Fütterung und Pflege wie sie selbst benötigen.

Einen etwas tragischeren Ausgang nimmt da die Geschichte einer Schildkröte, die des Esseintes zunächst einmal mit einem golden eingefärbten Panzer ausstatten lässt, bevor er sie zum Juwelier schickt, der genau nach seinen Angaben den Panzer der güldenen Schildkröte mit Gemmen und allerlei Edelsteinen verziert. Das alles ist wunderbar anzuschauen und des Esseintes ist anfänglich begeistert! Dumm nur, dass sich die Schildkröte einige Tage lang nicht mehr bewegt, so dass ihr Besitzer dann doch bemerkt, dass sie längst das Zeitliche gesegnet hat, wohl nicht zuletzt aufgrund der Tatsache, dass sie den blendenden Luxus nicht länger hatte ertragen können. Sie konnte sich gleichsam im Buch der Natur nicht mehr finden.

Doch all dies bleibt dem ausgesperrten Publikum, den Bewohnern von Fontenay-aux-Roses, sorgfältig verborgen. Des Esseintes ist mit allen Wassern und Düften eines Dandy gewaschen, aber wir dürfen uns gleichwohl fragen: Ist er es überhaupt noch? Denn eigentlich zielt ein Dandy auf möglichst großen Effekt in der Öffentlichkeit und braucht die Wirkung, die Auseinandersetzung 
um seine Kleidung, seine Sitten, seinen Lebensstil und Ansichten. Nichts dergleichen aber ist nach dem Rückzug von des Esseintes in sein abgelegenes Haus zu beobachten. Er ist nun nicht mehr den Blicken der anderen ausgesetzt und versucht vielmehr, sich diesen unschönen Physiognomien zu entziehen und allein in seiner Parallelwelt $\mathrm{zu}$ leben.

Man könnte sagen, dass des Esseintes eigentlich kein Idealtyp des Dandy ist und seit seinem Rückzug vielleicht überhaupt nicht mehr als ein solcher gelten kann. Die breite Bevölkerung ist ihm schnuppe, ein Spezialistenpublikum aber erreicht er nicht (mehr). Dies gilt es bei den nachfolgenden Analysen im Gedächtnis zu behalten!

Festhalten wollen wir an dieser Stelle, dass die Kunst des Fin de siècle in aller Regel eine Kunst der Innenräume, der räumlichen Abgeschlossenheit, der Trennung von der Natur in einem Reich des Inneren, der Künstlichkeit, der Nachahmung, der Isolierung, der Eigengesetzlichkeit ist. Die Natur wird vehement bekämpft, ihr Reich gleichsam ausgesperrt. Sie findet nur in vielfach destillierter Form, verwandelt in die Genüsse des Gaumens und der Sinne, transponiert in die Kunst in ihren unterschiedlichen Ausdrucksformen, Eingang in das Repertoire der Innenräume.

Wir werden dies auch an den imaginären Reisen erkennen können, die fortan ebenfalls in Innenräumen angesiedelt werden. In dieser Hinsicht ließe sich des Esseintes durchaus mit den Helden von Jules Verne vergleichen, der - wie Roland Barthes in einer seiner Mythologies einmal schrieb - im Grunde nur Innenräume zu füllen verstand, ein Reich der Fülle schuf, dem das Äußere höchstens bedrohlich entgegenstand.

Im fünften Kapitel kommen wir zu einer Szenerie, die eine gewisse Zentralstellung in Huysmans' Roman einnimmt: Es geht um die Auseinandersetzung mit der Malerei nicht nur Odilon Redons, sondern weit mehr noch mit jener von Gustave Moreau, die des Esseintes (und natürlich auch Huysmans selbst) tief beeindruckt hatte. So verliert sich der noch junge französische Adelige gleich zu Beginn des Kapitels in eine Träumerei über zwei Gemälde, welche er in einer meisterhaften Ekphrasis literarisch darzustellen sucht. Da es sich bei diesem fünften Kapitel um einen der Höhepunkte und auch auf theoretischer Ebene um eine der interessantesten Passagen des Buches handelt, möchte ich mich hier ein wenig aufhalten und einige Aspekte etwas näher beleuchten:

Unter allen Künstlern existierte einer, dessen Talent ihn entzückte und zu langen Gefühlsbewegungen hinriss, Gustave Moreau.

Er hatte seine beiden Meisterwerke erworben und träumte nächtelang vor einem von beiden, dem Gemälde der Salome, das auf die folgende Weise konzipiert war: 
Ein Thron erhob sich, einem Altare in einer Kathedrale gleich, unter unzählbaren Bögen, hervorspringend zwischen gedrungenen Säulen sowie romanischen Pfeilern, von vielfarbigen Ziegelsteinen und Mosaiken überzogen, mit eingefassten Lapislazuli und Sartonyx-Steinen, alles in einem Palast, der einer Basilika glich, deren Architektur zugleich halb muslimisch und halb byzantinisch war.

Im Mittelpunkt des den Altar überragenden Tabernakels, von Stufen in halbrunder Beckenform umgeben, saß der Tetrarch Herodes, das Haupt von einer Tiara geschmückt, beide Beine eng beieinander und die Hände auf seinen Knien haltend.

Sein Gesicht war gelblich, pergamentartig, von Falten durchfurcht, vom Alter entstellt; sein langer Bart schwebte wie eine weiße Wolke über den edelsteinfunkelnden Sternen, welche die Konstellation seines Gewandes aus Goldplattierkunst an seiner Brust bildeten.

Um diese unbewegliche, in der hieratischen Pose eines Hindugottes fixierte Statue herum brannten Duftessenzen, aus denen Wolken von Dämpfen hervorquollen, welche die Feuer der an den Wänden des Thrones inkrustierten Edelsteine, phosphoreszierenden Tieraugen gleich, durchbohrten; dann hob sich der Dampf, und unter den Arkaden vermischte sich der blaue Rauch mit dem Goldpulver der großen Lichtstrahlen, die von den Kuppeln herab einfielen.

Im perversen Duft der Parfums, in der überhitzten Atmosphäre dieser Kirche, streckte Salome ihre linke Hand in einer befehlenden Geste aus, während ihr rechter Arm angewinkelt blieb und auf der Höhe ihres Gesichts eine große Lotusblume hielt, und sie bewegt sich langsam auf den Zehenspitzen vorwärts, zu den Klängen einer Gitarre, deren Saiten eine kauernde Frau zupft.

Mit einem konzentrierten Gesichtsausdruck beginnt sie feierlich, fast erhaben, mit ihrem lüsternen Tanz, der die schläfrigen Sinne des alten Tetrarchen wachrütteln soll; ihre Brüste wogen hin und her, und ihre Brustspitzen richten sich bei der Reibung ihrer Colliers, die herumwirbeln, auf; über der Feuchtigkeit ihrer Haut funkeln die aufgefädelten Diamanten; ihre Armreife, ihre Gürtel, ihre Ringe versprühen Funken; auf ihrem triumphalen Kleid, das von Perlen gesäumt, von Silber durchwirkt, von Gold durchwoben ist, gerät der Brustpanzer vollendeter Goldschmiedekunst, an welchem jede Masche eine Perle ist, in Brand, durchquert kleine feurige Schlangen, kribbelt auf dem mattglänzenden Fleisch, auf der teerosafarbenen Haut, so wie gewaltige Insekten mit alles überstrahlenden, karminfarben gezeichneten Flügeldecken, vom gelben Tagesanbruch punktiert, von einem Stahlblau durchzogen, pfauengrün gescheckt.

Konzentriert und mit starren Augen, wie eine Schlafwandlerin, sieht sie weder den Tetrarchen, der erzittert, noch ihre Mutter, die grausame Hérodias, die sie überwacht, noch den Hermaphroditen oder Eunuchen, der sich unterhalb des Thrones mit dem Säbel in der Faust aufhält, ein schreckliches Antlitz, bis zu den Wangen hoch verschleiert, und dessen weibliche Brust eines Kastrierten wie ein Trinksack unter seiner orangebunten Tunika baumelt. Dieser Typus von Salomé, der die Künstler wie die Dichter so sehr fesselt, war seit langen Jahren eine Obsession für des Esseintes. ${ }^{7}$

Da haben wir sie also doch, die Frau und ihre erotisierende Beschreibung! Wenn also Huysmans behauptet, in seinem Roman gänzlich ohne die Frau, ohne die

7 Huysmans, Joris-Karl: A rebours, S. $67 \mathrm{ff}$. 


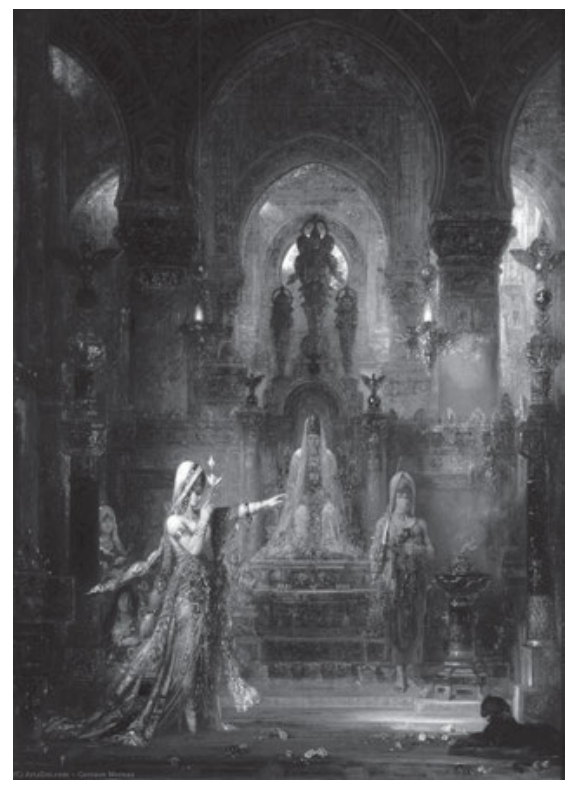

Abb. 108: „Salomé dansant devant Hérode“, Öl auf Leinwand von Gustave Moreau, 1876.

Liebe, auszukommen, dann stimmt dies schlicht nicht. Natürlich sind es entweder die gymnastischen Leibesübungen und Stellungsspiele oder die Liebe als Trieb, welche die romanesken Szenen von A rebours prägen, und keine eigentliche Liebesgeschichte, die sich auf oder zwischen den Zeilen des Romans entrollt; aber gänzlich ohne die Präsenz von Liebe, Sexualität und Erotik kommt auch dieser Roman entgegen der Behauptungen seines Verfassers nicht aus.

In diesem langen Zitat, das wir gleich zu Anfang des fünften Kapitels finden, präsentiert Huysmans uns ein Meisterwerk der Ekphrasis, also der literarischen Umsetzung ikonischer Texte in (Schrift-)Sprache mit allen Raffinessen, die ein Schriftsteller der literarischen Transposition abgewinnen und entreißen kann: So sind auf dem Gemälde von Gustave Moreau bestimmt nicht die Brustspitzen der schönen Salome erkennbar, wie sie sich aufgrund der Reibung an ihren Gehängen aufrichten und bewegen. Aber genau darüber, ihren ästhetischen Mehrwert und Überschuss, müssen wir bei einer literarischen Ekphrasis detailliert sprechen, denn es geht hier um die literarische Lektüre eines Gemäldes, die mit allen Charakteristika eines Leseaktes ausgezeichnet ist und damit um ein höchst kreatives LiebeLesen.

Ich möchte Ihnen daher diese Passage, die in der Wortwahl überaus komplex ist, gleich zweimal in Erinnerung rufen: einmal nur in Form des schriftlichen Textes und ein zweites Mal kombiniert mit einer Wiedergabe des berühmten Gemäldes von Gustave Moreau, das diesen Text begleitet. 
Wir erfahren zunächst vom Erzähler, dass es sich im Privatbesitz von des Esseintes befindet, der es mit in sein Haus in Fontenay-aux-Roses genommen habe. Dort hängt es zusammen mit anderen Meisterwerken, nicht zuletzt Gemälden von El Greco als einem der großen Maler, die das Fin de siècle nicht nur in Spanien zelebrierte, in der Innerlichkeit der Räume und Säle, wobei auch das Bild selbst die Struktur des Innenraumes in Szene setzt. Denn Licht von außen dringt in dieses Bildnis der tanzenden Salome höchstens von den hohen Kuppeln im Gemälde herab in den abgeschlossenen, mit einer Basilika verglichenen Innenraum.

Des Esseintes aber, dies macht der kleine Satz zu Anfang deutlich, ist selbst Kunstsammler: Seine fürwahr erlesene Kollektion verwandelt das Haus in Fontenay in ein Museum, und zwar auf verschiedenen Ebenen. Denn er sammelt nicht nur wertvolle Gemälde, sondern auch andere Kunstgegenstände, die sorgfältigst ausgewählt werden. Darauf können wir im Rahmen unserer Liebe und Lesen gewidmeten Vorlesung sicherlich nicht in der erforderlichen Breite eingehen, aber die Struktur des Museums und des musée imaginaire ist eine Art Grundstruktur der Literatur der Jahrhundertwende; ein Phänomen, das natürlich an kostbar gestaltete Innenräume gebunden ist.

Die kunstvolle Ekphrasis bezieht sich auf ein Gemälde von Gustave Moreau aus dem Jahre 1876. Dieses Gemälde hält eben jenen Augenblick fest, in welchem der Tanz der Salomé beginnt, der Übergang also von der Bewegungslosigkeit zur Bewegung, in der Ekphrasis von Huysmans der Übergang von der zeitlichen Hintergrundgestaltung in die präsentisch gestaltete Passage, die gleichsam alles zugleich in ein unmittelbares Licht im Vordergrund und in die Offenheit aller Bewegungen taucht.

Anhand der biblischen Geschichte, die des Esseintes auch durch Lektüre der einschlägigen Passagen aus dem Matthäus-Evangelium nachvollzieht - ich überlasse dies ihrer eigenen Lektüre -, identifiziert Huysmans' Erzähler die verschiedenen Gestalten, die mehr oder minder im Hintergrund verharren, doch zumindest vorübergehend von ihm literarisch in Licht getaucht werden. Sie sind fast eingewoben in jene sinnliche Architektur, die in der Ekphrasis zunächst detailreich entfaltet wird: mit ihrer mehrschichtig vielgewölbten Baustruktur der Bögen und Architraven, die kaum einmal das Licht direkt passieren lassen, so dass das Intérieur plastisch hervortritt.

Alles betont die Eigenwelt des Innenraumes, wenn auch genügend Licht einfällt, um die eigentliche Hauptszene beleuchten zu können. Alles wirkt ungeheuer symbolisch und erotisch aufgeladen, mehrfach kodiert, rätselhaft und voller geheimer geschlechtlicher Bedeutungen, wobei die Körperlichkeit der erregenden Salomé durch das Präsentische in Huysmans Text gleichsam auf 
den Leser und die Leserin überspringt. Was in Moreaus Gemälde in einer fast quasi-simultanen Wahrnehmung zusammengesetzt wird, einer Art von offenem, multidirektionalen Weg durch das Gemälde, der ein ständiges Pendeln zwischen einer Wahrnehmung der Gesamtheit und einzelner Details darstellt, ist in der Sprache des Schriftstellers ein In-Bewegung-Setzen aller Teile der Beschreibung, um so die Leserinnen und Leser dieses Textes in eine Abfolge einzelner Wahrnehmungen einbeziehen zu können. Hier ist die quasi-simultane Wahrnehmung verschriftlicht und transponiert in eine Wahrnehmung, die notwendig linear und vor allem sukzessiv ist und daher nach Erzählung, nach dem Narrativen drängt. Und dem gibt Joris-Karl Huysmans genügend Raum.

Der französische Maler Gustave Moreau, der 1826 in Paris geboren und 1898 ebendort verstorben ist, zählte zweifellos zu jenen Künstlern, die das Fin de siècle erstmals in Wert setzte, ohne sie freilich gänzlich aus einer gewissen Randstellung befreien zu können. Ähnlich ging es einem anderen Künstler, Odilon Redon, der ebenfalls zu den Lieblingsmalern Huysmans gehörte, der ihm eine Reihe von Kunstkritiken widmete, und welcher von zahlreichen Autoren des Jahrhundertendes wertgeschätzt wurde, ohne doch ein wirklich breites Publikum dauerhaft erreichen zu können. Gustave Moreau freilich gilt bis heute als Meister des französischen Symbolismus in der Malerei. Er verstand es, ausgehend von mythologischen oder biblischen Stoffen die weibliche Schönheit in den raffiniertesten Inszenierungen darzustellen, in einer symbolischen und nicht selten erotischen Aufladung, wie am Beispiel dieser ersten Salomé anschaulich erkennbar wird.

Er darf zweifellos als jener Maler gelten, dem es am überzeugendsten gelang, die raffiniertesten Stoffe, Edelsteine, Lichtbrechungen, Hautfarben und vieles mehr in seine Gemälde einzubringen und Synästhesien hervorzurufen, wie sie die Sinnlichkeit des europäischen wie außereuropäischen Fin de siècle so sehr liebte. Der französische Maler machte nicht zuletzt auch durch neue Interpretationen der Mythologie von sich reden, insoweit er altbekannten Stoffen eine neue Wendung gab. Er war ein Meister dessen, was wir mit Hans Blumenberg als Arbeit am Mythos bezeichnen dürfen. ${ }^{8}$ Auch in dieser Interpretation ist es nicht mehr Hérodias, die Mutter der schönen Salome, die durch ihre Tochter bewirkt, dass der Kopf von Johannes dem Täufer fällt, sondern vielmehr Salome selbst, die im wahrsten Sinne des Wortes in Aktion tritt. Sehen wir uns also diese Salome einmal etwas näher an, um zu erfahren, wie die Bibellektüre Moreaus unter der Feder von Huysmans und dessen Lektüre von Moreau literarische Dimensionen erreicht!

8 Vgl. Blumenberg, Hans: Arbeit am Mythos. Frankfurt am Main: Suhrkamp 1979. 


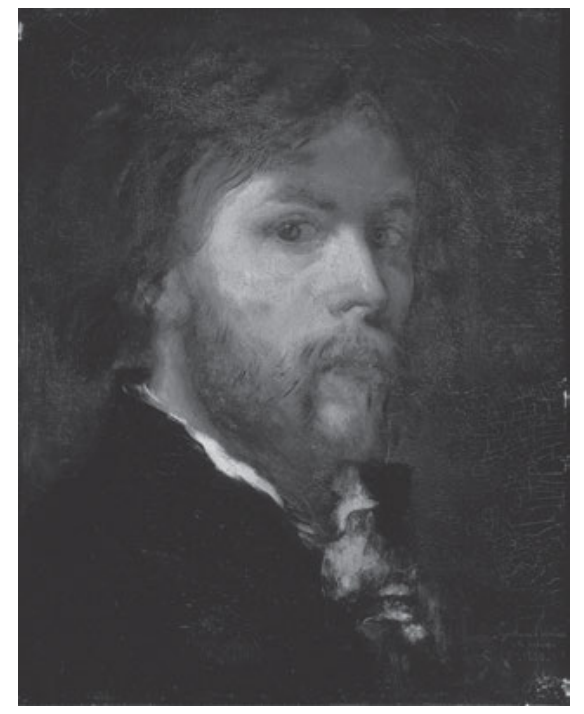

Abb. 109: Selbstporträt von Gustave Moreau, 1850.

Die Sinnlichkeit dieser Szene, die einen biblischen Stoff in eine noch orientalischere Szenerie einrückt, ist kaum zu überbieten und erinnert nicht von ungefähr an Flauberts Salammbô, die der Schöpfer der Education sentimentale unter Betonung einer erotisch aufgeladenen Frauenfigur ja auch aus der Bibel destilliert hatte. Das biblische Hohelied steht im Hintergrund all dieser Schöpfungen der Malerei wie der Schreibkunst; der Orientalismus, die Suche nach dem Exotischen, kulturell Anderen in einer konsumierbaren, im Orient verorteten Form, ist hier mit Händen greifbar und transportiert alle Legenden und Erwartungen gegenüber Sinnlichkeit und weiblicher Schönheit, welche das Publikum der zweiten Hälfte des 19. Jahrhunderts nicht nur in Frankreich auf derartige Sujets projizierte. Salome steht hier wie Salammbô im Schnittpunkt vielfacher künstlerisch-literarischer Traditionslinien.

Ist die Umsetzung der visuellen Bewegung in literarische, nicht-simultane Bewegung eines der Hauptcharakteristika dieser Ekphrasis, so ist auch von Interesse, dass zugleich die Gerüche, die exotischen Düfte und Parfums, gleichsam aus dem Bild herausdestilliert und literarisch präsent gemacht werden. Erst vor dem Hintergrund dieser perversen Düfte beginnt Salome mit ihrem Tanz, der dann bei Oscar Wilde einen weiteren literarischen Höhepunkt im Tanz der sieben Schleier erreichen wird.

Nicht nur die Sinne des uralten Herodes, sondern auch des Publikums werden beansprucht, wobei Huysmans' Prosa die körperlichen Attribute der Salome in ihrer Nacktheit noch stärker ins Bild rückt als Moreaus Gemälde. Zugleich werden bei Huysmans Bewegungen bevorzugt, wie etwa das Aufstellen 
der Brustspitzen der Salomé, was der Betrachter des Gemäldes ja eigentlich nicht wahrnehmen und schon gar nicht als körperlich-sensuelle Bewegung fassen kann. Huysmans führt also literarisch gesprochen eine continuation oder Verschärfung der Bildvorlage durch, mit welcher er hier in einen Dialog, zugleich aber auch in einen Wettstreit der Künste eintritt. Wir haben es mit einer raffinierten intermedialen Lektüre zu tun, die zugleich ein intermedial produktives Schreiben darstellt. Des Esseintes erweist sich als begnadeter und aktiver Leser eines Malers und eines Gemäldes, das wiederum der Lektüre durch die Leserschaft geöffnet wird. Durch Ekphrasis sehen wir Huysmans gleichsam bei dessen Leseakt über die Schulter und begreifen seine Lektüre als intermedialen Dialog.

Der Traumcharakter dieser Szene wird mehrfach unterstrichen, wobei Begriffe wie „Obsession“ oder „Schlafwandlerin“ im Romantext selbst diese Assoziationen aufrufen. Salomé ist in Trance, sie unterliegt selbst der Magie des Augenblicks und der verführerischen Kraft der Lotusblume, die sie in ihrer Rechten hält. Die ganze weibliche Sinnlichkeit, aber auch - wie des Esseintes durchaus weiß und zum Ausdruck bringt - die männliche, phallische Dimension sind in dieser Geste zum Ausdruck gebracht.

Zugleich symbolisiert die ausgestreckte linke Hand das Begehren, das sich zugleich auf den Mann (und damit Eros) und den Tod (Thanatos) richtet. Die Darstellung eines Hermaphroditen, der halb verschleiert mit großen Füßen vor uns steht, ist hier nur die Fortsetzung einer erotisch ungeheuer aufgeladenen Szenerie, wobei wir natürlich wissen, dass dem Hermaphroditen, dem Zwitterwesen, gerade im Fin de siècle eine besonders große Bedeutung zuteilwurde. Stets war - wie auch im zurückliegenden Jahrhundertende - die Unentschiedenheit und Unentscheidbarkeit gerade auch in geschlechtlichen Dingen ein Faszinosum, welches Kunst und Künstler^innen anlockte.

So können wir festhalten, dass in diesem Gemälde, durch eine meisterhafte Ekphrasis erhellt, die verschiedensten Sinne zusammenströmen in einer Synästhesie, die auch die literarische Sprache selbst beseelt: Düfte, Farben, Haut und Körperlichkeit, Musik, Tanz, Rhythmen, taktile Erfahrungen und körperliche Bewegungen, alles strömt hier zusammen und kulminiert in einem Tanz des Begehrens einer femme fatale, die nicht nur das Objekt ihrer Begierde, sondern auch sich selbst zugrunde richtet und in den nahen Tod reißt.

Doch wir sollten nicht nur dieses eine Gemälde von Gustave Moreau, sondern auch sein zweites für unsere Beschäftigung mit diesem Kapitel heranziehen, ein Gemälde, das - wie Sie sahen - vom Erzähler direkt erwähnt wird! Huysmans beziehungsweise des Esseintes konstruiert zwischen dem ersten und diesem etwas später entstandenen Bild eine zeitliche Sequenz, die im Sujet in der Tat 
angelegt ist, betont dies aber durch eine grundlegend narrative Struktur und Erzählweise in ungewöhnlich verstärkender Weise.

In diesem zweiten Gemälde ist Salomé bereits am Ziel ihrer Wünsche: Sie hat, wie es ihre Mutter wollte, vom Tetrarchen Herodes, ihrem Stiefvater, das geforderte Geschenk für ihren lasziven Tanz erhalten, der nunmehr zu Ende ist. Es erscheint ihr nun der abgeschlagene Kopf von Johannes dem Täufer, der ein letztes Mal zu ihr spricht. Sie ist fast gänzlich entblößt; und in ihrer bedeckten Nacktheit steht sie dem keuschen Täufer und Propheten gegenüber, der ihr nunmehr geradezu in Gestalt eines Christus entgegentritt. Die Erscheinung des Göttlichen, des Transzendenten, überstrahlt das Fleischliche und die Lust, ohne diese doch vollkommen auslöschen zu können. Schauen wir uns diese Szenerie in $A$ rebours etwas näher an!

Das abgetrennte Haupt des Heiligen hatte sich von dem Tablett erhoben, das auf den Fußboden gestellt war, und betrachtete alles bleich und mit entfärbtem Munde, mit aufgerissenen Augen und mit puterrotem Kragen, Tränen vergießend. Ein Mosaik umschloss das Gesicht, von dem ein Heiligenschein ausging und Lichtstrahlen unter den Portalen verströmte und dabei den grässlichen Aufstieg des Kopfes beleuchtete und das gläserne Rund der Augäpfel erhellte, welche irgendwie krampfhaft auf die Tänzerin gerichtet waren.

Mit einer Geste des Erschauerns wehrte Salome die Schrecken verbreitende Vision ab, die sie förmlich festschraubte, unbeweglich auf ihren Spitzen; ihre Augen weiten sich, ihre Hand umfasst konvulsiv ihre Brust und ihren Hals.

Sie ist fast nackt; in der Hitze ihres Tanzes hatten sich die Schleier gelöst, ihre Brokatspangen sind zerbrochen; sie ist allein noch mit Goldschmiedeobjekten und leuchtenden Mineralien bekleidet; ein Büstenstöffchen wie auch ein kleines Korsett pressen ihre Taille, und wie eine phantastische Spange züngelt ein wunderbarer Edelstein mit funkelndem Glanz im Zwischenraum ihrer beiden Brüste; tiefer noch, an ihrer Hüfte, umschlingt sie ein Gürtel, den oberen Teil ihrer Schenkel verbergend, welche von einem gigantischen Gehänge gestoßen werden, worin ein ganzer Fluss von Karfunkeln und Smaragden seinen Lauf nimmt; auf ihrem gänzlich nackten Körper schließlich, zwischen Büstenstöffchen und Gürtel, ein hervorstehender Bauch mit einem tief eingefurchten Bauchnabel, der in seiner Tiefe einem Siegel aus Onyx gleicht mit den milchigen Tönen in der rosafarbenen Färbung von Fingernägeln.

Noch immer blutend strahlt das grässliche Haupt, wobei es purpurdunkle Klumpen an den Spitzen des Bartes wie der Haare aufweist. Allein für Salome sichtbar, umschlingt sie mit ihrem düsteren Blick nicht die Hérodias, die ihren endlich ans Ziel gekommenen Hassgefühlen nachträumt, wobei der Tetrarch, ein wenig vornüber gebeugt und seine Hände auf den Knien haltend, noch immer keucht, verrückt nach jener Nacktheit einer Frau, die unverändert nach wilden Gerüchen duftet, in Balsam gerollt, getaucht in den Rauch von Weihrauch und Myrrhe. ${ }^{9}$

9 Huysmans, Joris-Karl: A rebours, S. 73f. 


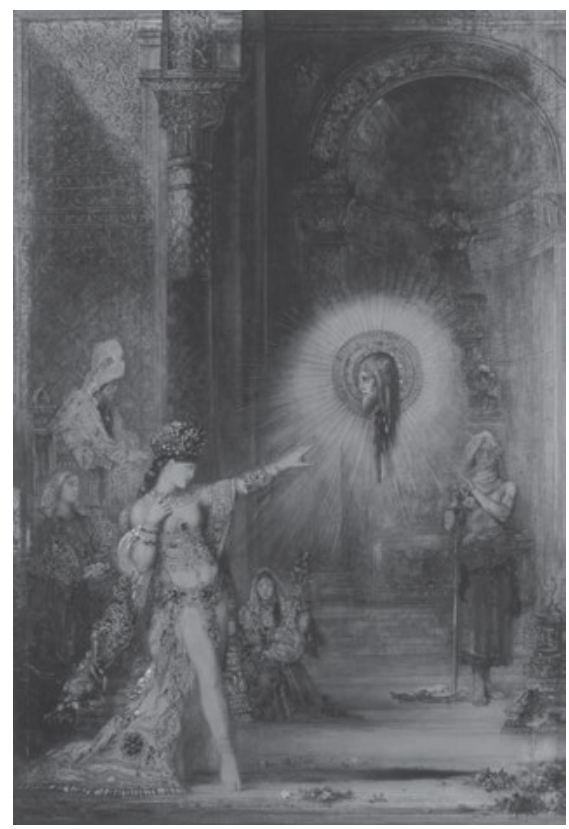

Abb. 110: „L'Apparition“, Aquarell von Gustave Moreau, circa 1876.

Welch eine perverse, kurz nach dem Blutbad, nach der Enthauptung von Johannes dem Täufer festgehaltene Szenerie, die etwas vom kleinen Tod nach einem mitreißenden Höhepunkt an sich hat! Noch einmal versucht hier des Esseintes beziehungsweise die Erzählerfigur, uns das Gemälde in eine lineare Zeitachse der Narrativität zu übersetzen. Überall sehen wir Auswirkungen, Konsequenzen, logische Abfolgen, welche die Gleichzeitigkeit des Bildes mit seiner simultanen Ambiguität freilich immer wieder nicht nur zeitlich, sondern auch semantisch festhalten.

In dieser Passage wird deutlich, dass Ekphrasis immer auch eine ganz bestimmte Deutung beinhaltet, dass also eine Vielzahl möglicher Abfolgen auf eine (oder wenig mehr als eine) reduziert wird, um die Plastizität des Bildes aufzubewahren. Dazu benötigt die Literatur die story, die Geschichte.

Zugleich zeigt sich, dass in einem Roman, der von der traditionellen Intrige, ja von der Frau und damit den Liebesaffären Abschied zu nehmen versucht, gerade diese Dimension über die Kunst und deren intermediale Nutzung in den Text eingeblendet wird, und zwar auf eine durchaus statische Weise. Denn es handelt sich hierbei keineswegs um die eigentlichen Beweggründe von des Esseintes. So ist die Sinnlichkeit und Körperlichkeit der Frau präsent, ist ihre Funktion als femme fatale sogar überdeutlich markiert, ohne dass doch die Geschichte des Protagonisten hierdurch wesentlich tangiert werden würde. 
Man kann darin in der Tat einen überaus geschickten literarischen Kunstgriff sehen, der mit sich bringt, dass das zeitgenössische Publikum zwar auf sex and crime verzichten musste auf Ebene der Haupthandlung, dass aber intermedial, mithin ekphrastisch, diese Dimension sehr wohl in den Roman Eingang fand. Zugleich wird die Brutalität des Mordes, der Tötung von Jokanaan, Johannes dem Täufer, auf eine überaus drastische Art dargestellt, ohne dass Huysmans auch hier auf eine Ästhetisierung des Geschehens verzichtet hätte. Denn auch dieser Spross einer Malerfamilie ist wie Gustave Moreau ein Maler der Farben, der dennoch mit Verlaine im fünfzehnten Kapitel des Buches feststellt, dass wir keine Farben, sondern nur Nuancen, immer nur Nuancen wollen.

Dies ist Huysmans hier gelungen, freilich auf der Basis deutlicher Farbkontraste und Schattierungen, die er Moreaus Gemälde entnahm. Auch bei ihm ist jene erotische Lust, jene künstlerische und zugleich künstliche Wollust zu beobachten, die später die Surrealisten in den Gemälden Gustave Moreaus erleben sollten. Denn sie erkannten in dem 1898 verstorbenen Maler, dem man zu Lebzeiten nachsagte, er sei zu literarisch und beladen, einen der großen Vorläufer surrealistischer Malerei. Bei Joris-Karl Huysmans ist bereits ein Vorgeschmack derartiger Deutungen im Lichte der geradezu traumartigen Sequenzen literarischer Ekphrasis zu erkennen.

Neben dem wechselseitigen Durchdringen von Gesichtssinn, Gehör, Olfaktischem und Taktilem ist das nicht weniger wechselseitige Spiel zwischen Fiktion und Realität bemerkenswert, das sich ausgehend von des Esseintes in Literatur und Gesellschaft des Fin de siècle ubiquitär finden lässt. Denn gerade auch im sinnlichen Bereich beeinflusst die Realität die Kunst und die Kunst wiederum die Realität in ständiger, unverminderter Wechselwirkung. So haben des Esseintes' Eskapaden - ich habe bereits darauf hingewiesen - eine Vielzahl weiterer Décadents und Dandys auf den Plan gerufen; viele begüterte und weniger begüterte Kunstfreunde dürften auch in seine Fußstapfen getreten sein oder dies doch zumindest als kleine Kunstmäzene versucht haben, denn nicht umsonst war der Roman eine Bibel und seine Hauptfigur Kult. Es handelt sich um das alte Problem der Übertragung fiktionaler Welten in die Realität und die daraus entstehende Umformung unserer Lebenswelt wie unserer Lebenswirklichkeit, also dessen, was jede Einzelne und jeder Einzelne von uns um sich als Elemente der Realität anerkennt. Ich möchte dies an einem einfachen, aber sicherlich überraschenden Beispiel belegen!

In dem sich unmittelbar an die Salome-Episode anschließenden sechsten Kapitel sehen wir des Esseintes bei der Lektüre. Wie wir am Ende des Kapitels erfahren, handelt es sich bei diesem Leseakt um ein lateinisches Gedicht des Wiener Bischofs Avitus mit dem schönen Titel De laude castitatis. In diesem Kapitel geht es kaum um das „Lob der Keuschheit“, auch wenn sich des Esseintes 
dieser zumindest hinsichtlich seines Körpers, wenn auch nicht hinsichtlich seines Denkens und Kunstempfindens verschrieben hat.

Seine Gedanken sind nämlich gänzlich unkeusch, denn er unterbricht seine Lektüre und denkt zurück an jene Episode in Paris, als er auf der Straße einen sechzehnjährigen Jungen traf, der ihn interessierte. Er beschloss, ihn zu verführen, freilich nicht auf jene Art, welche die Bordellbesitzerin später vermutete, als sie ihm sagte, er brauche wohl sehr junge Jungs für seine Begierden. Nein, des Esseintes hatte vielmehr vor, den jungen Mann zu einem Gegner der Gesellschaft zu machen, zu einem Feind jener hideuse société, die er längst zu hassen gelernt hatte.

Um dies zu bewerkstelligen, bringt des Esseintes den jungen, mit keinerlei Luxus vertrauten Mann in ein ihm bekanntes Bordell und lässt ihn zwischen den verschiedenen Frauen - und mehr noch den verschiedenen dort inszenierten Frauentypen - genüsslich wählen. Der Junge entscheidet sich schließlich für den Typ der schönen Jüdin, der in keinem Luxusbordell der Epoche fehlen durfte. So stoßen wir an dieser Stelle unvermutet auf eine Auswahl historischer Frauentypen, die für die Sinnlichkeit des Fin de siècle gerade für den Bereich der Literatur von großer Bedeutung sind.

Des Esseintes klärt die Bordellbesitzerin auf, er wolle dem Jungen einige Wochen lang diesen Genuss bieten, um ihn schließlich davon abhängig werden zu lassen. Da er danach nicht mehr über Geld verfüge, müsse sich der junge Mann den Luxus, auf den er dann nicht mehr verzichten könne, durch andere, kriminelle Wege sicherstellen. Auf diese Weise werde er sicherlich zu einem Raubmörder und damit weiteren Feind der Gesellschaft! Das ist recht interessant und mit einem gewissen surrealistischen Charme gedacht, geht aber freilich im Roman nicht auf, da des Esseintes zu seinem Verdruss in den sich anschließenden Monaten von keinem Raubmord aus den Gazetten erfährt, den der Junge begangen haben könnte. Doch wir interessieren uns hier noch für eine andere Dimension.

Denn bereits in dieser Szene wird deutlich, wie sehr die verschiedenen Frauentypen im Bordell gleichsam auf Bestellung verfügbar und vom Erwartungshorizont der Männer geprägt sind. Man darf zunächst darauf schließen, dass es sich bei einem Luxusbordell um eine Einrichtung handelt, die an den speziellen Bedürfnissen reicher, häufig adeliger oder großbürgerlicher männlicher Kundschaft ausgerichtet ist, und daher selbstverständlich auf dem neuesten Stand der Kunstentwicklung sein muss. Genau diesen Vorstellungen entsprechen auch die Modelle, die ,angeboten' oder ,feilgeboten' werden. So fällt es nicht schwer, Beziehungen herzustellen zwischen dem Bild der femme fatale - oder anderer Frauenfiguren - im Fin de siècle und jenen Prostituierten der Luxusbordelle, die für ihre finanziell potente Kundschaft versuchten, die entsprechenden Frauenbilder 
nachzuahmen und gleichsam die Kunstwerke in lebendige Körper zu verwandeln, die gegen Aufpreis zu haben waren. Zahlreiche Bildbände mit zeitgenössischen Photographien aus den établissements der Jahrhundertwende geben darüber Auskunft.

Wenn wir den Versuch unternehmen, die ikonische Darstellung der Frauenbilder in Literatur und Malerei, wohl aber auch in der Musik und spezifisch der Oper der Jahrhundertwende herauszusuchen und mit den Frauenfiguren in den Bordellen in Verbindung zu bringen, so fallen die enormen Übereinstimmungen, die sich dabei beobachten lassen, ins Auge. Denn man kann durchaus Moreaus tanzende Salome oder auch seine wenig später entstandene Galatea in Verbindung bringen mit historischen Photographien, die Prostituierte aus der Zeit der Jahrhundertwende zeigen. Dies gilt übrigens nicht allein für Europa, sondern nicht zuletzt auch für Lateinamerika, insbesondere Mexiko, wo einer neueren Untersuchung zufolge genau zum Zeitpunkt der Expansion des Bürgertums die Zahl der Prostituierten in Mexiko-Stadt exponentiell anstieg. Die Übereinstimmungen sind oftmals verblüffend und zeigen sich etwa in einem Band mit Photographien, die in jenen Jahren in mexikanischen Edel-Bordellen aufgenommen wurden. Man könnte durchaus einige dieser Photographien heraussuchen und neben die künstlerischen Modelle und Darstellungen von Frauen etwa in der Malerei Gustave Moreaus legen: der Effekt wäre verblüffend - aber auch verblüffend trivial!

Bezeichnend ist im Übrigen, dass des Esseintes an anderer Stelle darüber klagt, dass die Zahl der wirklich guten Luxusbordelle in Paris stetig ständig ab-, dafür aber die der billigen Absteigen erheblich zunehme, in denen man mit dem Bäckermädchen von gegenüber ins Bett steigen könne. Diese tue dies auch nicht umsonst, aber ohne jede Kunst! Auch auf diesem Gebiet also ist das raffinement, dem sich des Esseintes verschrieben hat, an eine gewisse wirtschaftliche und finanzielle Potenz, zugleich aber auch an die Erfahrung im Umgang mit Kunstwerken gebunden.

Die Kunst des Fin de siècle steht in Bezug auf ihre Frauenbilder in einem dialektischen Verhältnis zur Gesellschaft - dies sollten wir auch bei einem Roman nicht vergessen, der geradezu eine Arche-Struktur in einer mehrfachen Abkapselung von der Gesellschaft schafft. Doch genau dadurch, so könnten wir mit Marcel Proust sagen, wird die Welt besser gesehen und erkannt, denn von nirgendwo her eröffnet sich ein besserer Blick auf die Welt als von der Arche aus, auch wenn die Sonne verschwunden und alle Fenster des Schiffes geschlossen sind. Wir sehen damit zugleich: Die Literaturen der Welt sind auch in der Jahrhundertwende keineswegs wirklich am Ende, sie werden vielmehr von der Gesellschaft in so komplexer Weise mitgeprägt, dass sie ihrerseits in komplexer Weise auf diese Gesellschaft zurückwirken - und sei es in der ökonomischen Verfügbarmachung 
bestimmter künstlerischer Frauenfiguren. Die Abgeschlossenheit der Kunst und ihrer Traditionen erweist sich auch in dieser Hinsicht als Mythos der bürgerlichen Gesellschaft.

Die nachfolgenden Kapitel von $A$ rebours zeigen uns einen des Esseintes, der ständig kuriosen Aufwallungen seiner sehr speziellen Gelüste ausgesetzt ist und diese zum Teil selbst wiederum provoziert. So lässt er sich alle möglichen Arten exotischer Pflanzen herbeischaffen, von denen einige - wie die spätere Cattleya Marcel Prousts beziehungsweise Odette Swanns - aus der neuen Welt der Tropen stammen und die, ob fleischfressend oder nicht, stets etwas Fleischhaftes, Fleischliches und Erotisches an sich haben. Honni soit qui mal y pense.

Des Esseintes jedenfalls denkt beim Betrachten dieser exotischen Gewächse explizit über die den menschlichen Geschlechtsteilen ähnlichen Gebilde nach, worauf er bald schon deren Anblick zu meiden beginnt. Kein Wunder also, wenn er in der unmittelbar folgenden Szene einem Albtraum ausgesetzt ist, der sich leicht psychoanalytisch deuten ließe und ihn immer wieder im Bann des Erotischen und Körperlichen, zugleich aber auch der Kastrationsangst und der Angst zu versagen zeigt. Dabei kommt wie in der Salome-Episode dem Element der sich aufrichtenden Brustwarzen eine besondere Bedeutung zu, entspringen doch aus den Brustknospen - ein alter Topos - die Blumen des Bösen, die des Esseintes' Träume und Träumereien mit ihrer Sinnlichkeit betören.

Da ist es dann nicht weit $\mathrm{zu}$ anderen Ausdrucksformen und Lesarten, die als Aphrodisiakum auf seine erregte Einbildungskraft einwirken und ihn benommen zurücklassen. Nein, Erotik und Sexualität gehen ihm nicht aus dem Kopf, mag er sich noch so sehr darum bemühen! Selbst beim Lesen der Romane von Charles Dickens wird er obsessiv von der Sinnlichkeit angezogen, gerade weil die Heldinnen des englischen Schriftstellers so keusch zu Boden blicken und entweder erröten oder vor lauter banalem Glück zu weinen beginnen. Immer mehr wird des Esseintes in die Abgründe des Erotischen hinabgezogen, eine Phase, die zuvor schon in pathologischen Termini als Neurose beschrieben worden war. Das Leitmotiv der Erotik ist in all diesen Äußerungsformen, seien sie künstlerischer oder nicht-künstlerischer, stets aber künstlicher Art, unverändert und unvermindert wiederzuerkennen. Charles Baudelaires Blumen des Bösen standen hier ohne jeden Zweifel Pate.

Auch für die Ausführungen des zehnten Kapitels sind die diesmal explizit gemachten Gedichte Baudelaires als stimulierende Anregungsmittel nicht wegzudenken. Sie sind hier also Teile des expliziten literarischen Raumes und betreffen nun die verschiedenen Düfte, die unseren Helden auf seiner Abenteuerreise durch die Welt der Sinne begleiten. In diesem Kapitel tut sich erneut eine eigene 
Welt auf, die von des Esseintes erfahren und zugleich durchfahren wird, bevor er am Ende auch hier wieder ermattet zusammensinkt. Er wird von der Schwäche seines Blutes übermannt, einer Schwäche, die im scharfen Kontrast zur jungen und starken US-amerikanischen Trapezkünstlerin und Artistin steht, welche er einst als Mätresse besaß. Zweifellos haben wir es hier mit einer Anspielung auf die biologische und materielle Überlegenheit der angelsächsischen ,Rasse zu tun, auch wenn ihm die blonde Miss Urania, mit großen fleischfressenden Zähnen bewehrt, an künstlerischer Verfeinerung weit unterlegen ist. Sie schafft es nicht einmal, die sich bei ihm manifestierende ephemere Geschlechtsveränderung zu fixieren, um selbst dauerhaft zur männlichen Figur zu werden und ihn in die passive Weiblichkeit lustvoll und genderqueerend $\mathrm{zu}$ locken. Nein, das konnte nicht lange gutgehen! Die Begegnung zwischen der starken Angelsächsin und dem schwachen, aber verfeinerten Romanen war nur von kurzer Dauer, zumal ihre erotische Prüderie bei ihm seriöse Potenzstörungen hervorrief.

Aber zurück zum Reich der Düfte, das natürlich nicht nur bei des Esseintes mit der Erinnerung unmittelbar verkoppelt ist! Nicht von ungefähr sind die am weitesten in unserem Gedächtnis zurückreichenden Erinnerungsspuren Düfte und Gerüche, die wir mit bestimmten Umgebungen und Erfahrungen unserer Kindheit in Verbindung bringen. Für des Esseintes ist dies selbstverständlich auch eine Kunst, eine Chance zum Raffinement und eine erhebliche Erweiterung künstlerischer Ausdrucksformen in einer sinnlich aufgeladenen Welt abgeschlossener Innenräume.

Wir dürfen aus all diesen Passagen folgern, dass in Huysmans’ Roman die Frau, la femme, in keiner Weise fehlt. Sie ist nicht mehr zum Antriebsmotor der Erzählung oder des Erzählens geworden, sondern hat eine stärker statische Funktion, die gleichwohl eine Art obsessiver Allgegenwart heraufbeschwört. Die Frau ist in der Tat nur fast omnipräsent, denn in der Kunst fehlt sie völlig, wenn nicht als Objekt, so doch als Subjekt. Wir können dennoch festhalten, dass weder die femme noch die passion in des Esseintes Kaleidoskop menschlicher Leidenschaften fehlen und wohl auch nicht fehlen dürfen. Ganz so radikal war er also nicht, der angekündigte und angepriesene Traditionsbruch!

Für unsere Fragestellungen besonders interessant scheint ein Kapitel, in dem die Frauen praktisch überhaupt keine Rolle spielen, und zwar das vierzehnte. In ihm geht es um die französische Literatur des 19. Jahrhunderts, die vor den Augen des Lesers und der Leserin sehr intensiv, jedoch nur anhand einiger weniger Beispiele diskutiert wird. Wir hatten bereits bemerkt, dass seit dem Paratext und den ersten Seiten des Romans der Aufbau eines literarischen Raumes mit großer Intensität betrieben wurde. Wir hatten ferner festgestellt, dass dieser literarische Raum ergänzt wurde durch einen Raum, den wir ohne Zögern als künstlerischen 
Raum bezeichnen können, in dessen Zentrum zweifellos die französischen Maler Gustave Moreau und Odilon Redon stehen. Gewiss, es finden auch andere Künstler Erwähnung: so etwa der Spanier Goya oder der englische Präraffaelit Watts; und doch beherrschen die Franzosen ganz deutlich diesen künstlerischen Raum und übertreffen bei weitem jede andere Nation.

Dies ist auch beim spezifisch literarischen Raum der Fall. Wir haben gesehen, dass die lateinischen Autoren der Décadence bereits im Vordergrund eines literarischen Kanons der Literatur der Antike stehen, wobei des Esseintes stets die Spätzeiten bevorzugt. Dies ist in gewisser Weise auch bei jenem literarischen Raum der Fall, der nun in Bezug auf die zeitgenössische Literatur des 19. Jahrhunderts entfaltet wird. Dabei geschieht dies in Form einer Bibliothek und damit einer Präsentationsform, die wir im Verlauf unserer Vorlesung bereits kennengelernt haben.

Denn der ermattete und erschöpfte des Esseintes ordnet seine bestehende Bibliothek neu, indem er sich, die eigenen Kräfte schonend, von seinem Domestiken die Bücher bringen lässt und dann anordnet, in welchem Bereich die einzelnen Bände wieder aufgestellt werden sollten. Die Bibliothek im Roman, das Buch im Buch in Form der Bibliothek, ist zweifellos ein Topos, der gewiss nicht von Huysmans ausgeht, der wohl aber von ihm aus neuen Schwung in die Literaturen des Fin de siècle und weit darüber hinaus gebracht hat. Nicht nur in der französischen Literatur ist dies $\mathrm{zu}$ bemerken; auch in der lateinamerikanischen findet sich noch im selben Jahr 1884 mit José Martís Roman Amistad funesta ein Text, der deutlich im Zeichen Huysmans' ebenfalls eine interne Bibliothek aufstellt. Der gemeinsame, von beiden Bibliotheken geteilte Autor ist dabei übrigens Edgar Allan Poe, dessen Wirkung - nach den Übersetzungen Baudelaires - auf die Weltliteratur der zweiten Hälfte des 19. Jahrhunderts gar nicht überschätzt werden kann. Auch später finden sich literarische Texte, die diese interne Bibliothek geradezu auskosten, so etwa José Enrique Rodós Grundlagentext des Jahres 1900, Ariel. Selbstverständlich ordnet sich die Bibliothek der Dominanz der Innenräume zu und rückt die Verfeinerung aller Sitten und Usancen in den Mittelpunkt der Betrachtung.

Verwechseln wir aber nicht den literarischen Raum von des Esseintes mit dem von Huysmans: Wir dürfen nicht nur im autobiographischen, sondern auch im poetologischen Bereich beide nicht miteinander gleichsetzen, auch wenn es selbstverständlich eine Vielzahl von Berührungspunkten zwischen dem realen Autor und seiner literarischen Hauptfigur gibt! Des Esseintes' größte literarische Bezugsfigur der Vergangenheit ist jedenfalls der bereits mehrfach erwähnte Charles Baudelaire, dessen maßgebende Präsenz im Roman von keiner zweiten Dichtergestalt eingeholt wird. Er ist sowohl als Schöpfer von 
Gedichten als auch von poèmes en prose präsent, implizit sicherlich aber auch mit seiner Dichtungstheorie und nicht zuletzt als jener Dandy, als der er zeitweise in die Geschichte der französischen Literatur und Gesellschaft einging. Baudelaire darf als künstlerisch gestaltete Figur und damit als Verkörperung der Kunst im Leben gelten.

Die zweite große literarische Figur ist ein Nicht-Europäer, Edgar Allan Poe, den, wie erwähnt, Baudelaire ins Französische übersetzte und somit fast zu einem französischen Dichter machte. Sein literarisch-künstlerischer Rang ist kaum geringer als der Baudelaires, auch wenn in der Folge bezüglich der allzu keuschen Frauengestalten Poes von des Esseintes doch einige Abstriche gemacht werden. Zuvor aber werden eine Reihe französischer Größen der Literatur einen Kopf kürzer gemacht. Ja sicherlich, Victor Hugo sei schon ein großer Dichter, aber des Esseintes schätzt nicht die Mischung aus nettem Jungen und freundlichem Großvater, die allzu oft aus seinen Versen spreche: L'art d'être grand-père lässt grüßen!

Aber es gibt noch schärfere Korrekturen am Kanon: Leconte de Lisle, der große Dichter der französischen Romantik, hat abgedankt; seine Verse sind nur noch Fassaden- und Blendwerk. Überhaupt sei es weitgehend vorbei mit den großen Figuren der Romantik; währenddessen rückt die Generation spätromantischer Dichter und Schriftsteller ins erste Glied. Dabei lobt des Esseintes nicht nur die radikale Prosa von Léon Bloy, der später vorübergehend zu einem persönlichen Freund von Huysmans wurde, sondern auch Barbey d'Aurevilly, der - wen wundert's? - von Huysmans' Roman eine ebenso begeisterte Kritik und Rezension schrieb wie der erwähnte Bloy. Der dritte im Bunde ist Villiers de l'Isle-Adam, eine der großen verkannten Figuren der französischen Literaturgeschichte, die hier bei des Esseintes in die erste Reihe gestellt werden und alternativ-dekadent kanonisiert werden sollen. Nach Baudelaire ist es nicht mehr Théophile Gautier, sondern Verlaine, der die alten Traditionen dekadenter Lyrik weiterführe und zu neuen Höhen treibe.

Im Grunde vereinigt des Esseintes gerade im Bereich der Lyrik jene Dichter, die man als die poètes maudits bezeichnete. Wie sich das gehört, hatte des Esseintes auch eigene Anthologien anfertigen lassen, und zwar sowohl im Bereich der Dichtkunst als auch des poème en prose. Die in dieser eigenen Anthologisierung dominante Figur ist zweifellos Stéphane Mallarmé, der künftige große Fürst der französischen Dichtkunst für die Neoavantgarden und Theoriekonstrukteure der sechziger Jahre in Frankreich oder Italien. In Mallarmé, so scheint es, kommt die Dichtung Frankreichs zugleich zu ihrer vollen Blüte, zu ihrem vollen Bewusstsein und zugleich zu ihrem Ende. Denn die Literaturen stoßen in der Tat an ein Ende, das freilich mit Zukunft aufgeladen ist. Bei Huysmans begegnen wir dem Kern des künftigen Kanons französischer Literaten. Sehen wir uns dies etwas genauer an, 
bevor wir nochmals auf den literarischen Raum von des Esseintes beziehungsweise $A$ rebours zurückkommen!

Die für Huysmans' des Esseintes alles überragende literarische Gattung war auch dies natürlich im Gefolge seiner Verehrung des Dichterfürsten Baudelaire das poème en prose. Dies überrascht uns nicht, ist doch schon die Bezeichnung dieser Gattung paradox und verweist auf die kalkulierte Mischung von eigentlich Unzusammengehörigem, also auf die Überschreitung einer vermeintlich scharf gezogenen Grenze zwischen Prosa und Lyrik. Ausgehend von dieser Vorliebe meditiert des Esseintes über die Möglichkeiten der Literatur überhaupt; und diese Passagen haben im Grunde bis heute ebenso wenig von ihrer Aktualität und Schärfe verloren wie jene von Jorge Luis Borges. Sehen wir uns also einige Überlegungen aus den Schlusszeilen des vierzehnten Kapitels in der Folge etwas genauer an!

Häufig hatte des Esseintes über dieses beunruhigende Problem meditiert, einen verdichteten Roman in einigen wenigen Sätzen niederzuschreiben, welche das Konzentrat aus Hunderten von Seiten darstellten, die doch stets dazu dienten, das Milieu zu fixieren, die Charaktere zu zeichnen sowie zur Abstützung Beobachtungen und kleine Fakten aufzutürmen. Dann wären die einmal gewählten Worte so unwandelbar, dass sie alle anderen ersetzen würden; das Adjektiv, erst einmal auf so ingeniöse und definitive Weise gesetzt, dass es nach Recht und Gesetz nicht von seinem Platze entfernt werden könnte, würde derartige Perspektiven eröffnen, dass der Leser während ganzer Wochen über seine Bedeutung, welche präzise und vielfältig zugleich wäre, nachsinnen, die Gegenwart fixieren, die Vergangenheit rekonstruieren und die Zukunft der Seelen von Figuren erahnen müsste, welche vom Lichte dieses einzigen Adjektivs erhellt wären.

Der Roman, auf solche Weise konzipiert und kondensiert auf einer oder zwei Seiten, würde zu einer Kommunion des Denkens werden zwischen einem magischen Schriftsteller und einem idealen Leser, zu einer spirituellen Zusammenarbeit zwischen zehn höheren, über das ganze Universum verstreuten Persönlichkeiten, zu einem den Feinsinnigen servierten Genuss, der allein ihnen zugänglich wäre.

Mit einem Wort: Das poème en prose repräsentierte für des Esseintes dieses konkrete Konzentrat, das Osmazom der Literatur, ja die Essenz der Kunst. ${ }^{10}$

Da haben wir sie also wieder, die Vorstellung von der extremen Verdichtung, von der Destillierung einer Essenz, ganz im alchimistischen oder kabbalistischen Sinne, eine Vorstellung, die fast eine Art mystische Literaturbetrachtung bildet. Daher ist in einer gleichsam religiösen Wortwahl auch die Rede von einer communion der Geister, wobei wir zugleich die Figur eines idealen Lesers am Horizont der Literatur und mehr noch der Lektüre erscheinen sehen, welcher die literarische Kommunikation abrundet und quasi als aktives Lesemedium eine

10 Huysmans, Joris-Karl: A rebours, S. 260. 
wahrhaft dialogische Gesprächssituation errichtet, welche etwas zutiefst Spirituelles darstellt. Dass sich dies nur für die happy few des Geistes ermöglichen ließe, ist allen im Roman klar. Und so haben wir es auch bei der Leserschaft oder dem Publikum, das derlei noch verstehen könnte, mit einem extrem ausgewählten und erlesenen Kreis $\mathrm{zu}$ tun, welcher in diesem Zusammenhang gleichsam den suc, das Konzentrat und die Essenz der Literatur repräsentierte. Damit verbunden ist eine Aufwertung der Lektüre wie der Leser`innenrolle: Lesen würde so zu einer kreativen Aktivität, die sich auf Augenhöhe mit der Tätigkeit eines magischen Schriftstellers befände; Leserschaft und Autorschaft wären einander gleichgestellt.

Vergessen wir darüber jedoch nicht, dass die Grundüberlegungen Huysmans' zunächst einmal von bestimmten Worten oder Lexemen ausgehen, die einerseits ungeheuer präzise, andererseits aber auch überaus weite Assoziationsbereiche zulassen! Die Polysemie, die vielfältige Auslegbarkeit des literarischen Wortes wird dergestalt ins Zentrum des Systems Literatur gestellt.

Jedes Wort hat dabei seinen Platz; und es kann auch durch kein anderes Wort verdrängt oder ersetzt werden. Es ist in der Tat ein mot juste ganz im Sinne Gustave Flauberts, der den ,richtigen' Sitz seiner ,richtigen' Worte in seinem gueuloir, folglich durch Herausbrüllen dieser Worte, überprüfte. Alles stimmt in diesem idealen literarischen Text, der als Konzentrat eines Romans all die lästigen Beschreibungen, Milieudarstellungen und Persönlichkeitszeichnungen tilgt, welche gleichsam kommuniziert durch das mot juste nun im Lesepublikum evoziert werden und entstehen. Dies bringt eine unglaubliche Verdichtung der literarischen Arbeit ebenso auf Seiten der Autor- wie der Leserschaft mit sich.

Damit ist all das Lästige gleichsam der Kommunikation selbst, nicht mehr in seiner Weitschweifigkeit der kreativen Arbeit und schöpferischen Gestaltung überantwortet, so dass ein reines Destillat von Literatur entstehen kann. Der argentinische Schriftsteller Jorge Luis Borges hat sich ebenfalls - wie vor ihm Paul Valéry - mit derlei Verkürzungen und Verknappungen beschäftigt, ist es doch in der Tat eine beunruhigende Vorstellung, dass es möglich sein könnte, die so weitschweifigen Romane des 19. Jahrhunderts und auch noch der Jahrhundertwende so mir nichts dir nichts einzudampfen. Könnte daraus nicht eine neue Gattung entstehen, deren Würze in der Kürze läge?

Ich will an dieser Stelle nur kurz darauf verweisen, dass diese Überlegungen der Romanfigur des Esseintes, die auf das petit poème en prose hinauslaufen, sehr wohl als Grundlage einer Programmatik dienen könnten, welche im 20. Jahrhundert zur Entstehung einer neuen Gattung führte, die zwar nicht ohne Vorläufer 
war, aber doch etwas Neues in der Geschichte der Literaturen der Welt darstellte. Dieser literarhistorisch höchst relevante Prozess ergab sich weniger im französischsprachigen als im spanischsprachigen Raum und dort wiederum ausgehend von den hispanophonen Literaturen Lateinamerikas. Die Entwicklung hin zum microrrelato, zur Mikroerzählung oder insgesamt zu literarischen Kürzestformen, welche wohl am besten eine Nanophilologie untersuchen könnte, zeichnen sich auf diesen Seiten unleugbar ab und entwerfen das Bild einer Literatur, die es auf äußerste Verkürzung und Verknappung, zugleich aber auch auf größtmögliche Verdichtung und Kondensierung abgesehen hat. Doch uns fehlt die Zeit, uns im Rahmen unserer aktuellen Vorlesung mit der Entwicklung dieser literarischen Formen näher zu beschäftigen! ${ }^{11}$

All dies sind Vorstellungen, welche bald schon die Surrealisten und auch die späteren, nachfolgenden Avantgardisten begeisterten. Für unsere bisherigen Überlegungen ist es dabei von besonderer Bedeutung, dass es gerade die literarische Form ist, das poème en prose, das zum Inbegriff und zum Kondensat aller Künste wird. Denn es ist bei Huysmans keineswegs nur die Literatur gemeint: Des Esseintes sieht in der Kurzform des Prosagedichts jene künstlerische Form, in der alles gipfeln kann, zugleich aber auch dem Abgrund entgegentreibt. Nicht von ungefähr glaubt er am Ende des Kapitels nicht länger daran, dass er seine Bibliothek künftig in diesem Bereich noch einmal erweitern müsse. Ein Höhepunkt könnte erreicht sein, der zugleich auch ein alles konzentrierender Schlusspunkt der Literatur wäre.

Im gleichen Atemzug ist diese Vorstellung mit der nicht weit entfernten Idee verbunden, dass es sich hierbei um die Kunst einer Endzeit handeln könnte. Verfolgen wir die Überlegungen von des Esseintes also noch ein kleines Stückchen weiter:

In der Tat ist die Dekadenz einer Literatur, die irreparabel in ihrem Organismus beschädigt, geschwächt vom Alter ihrer Ideen, erschöpft von den Exzessen ihrer Syntax wäre sowie sensibel allein gegenüber den Kuriositäten, welche die Kranken fiebern lassen und gleichwohl daran ausgerichtet wäre, bei ihrem Untergang noch einmal alles zum Ausdruck zu bringen, versteift darauf, jedwedem Fehlen von Wollüsten entgegenzutreten, die subtilsten Erinnerungen an Schmerzen auf dem Totenbett noch weiterzugeben, in Mallarmé verkörpert, und zwar auf die vollkommenste und exquisiteste Art.

Dies waren, bis zu ihrem allerletzten Ausdruck getrieben, die Quintessenzen von Baudelaire und von Poe; dies waren ihre feinen und machtvollen Substanzen, nochmals destilliert, neue Düfte, neue Trunkenheiten ausatmend.

11 Vgl. hierzu Ette, Ottmar (Hg.): Nanophilologie. Literarische Kurz- und Kürzestformen in der Romania. Tübingen: Max Niemeyer Verlag 2008. 
Dies war die Agonie der alten Sprache, welche, angereichert von Jahrhundert zu Jahrhundert, sich schließlich auflöste, den Punkt erreichte, wo die alte lateinische Sprache zerfloss, die sich in den mysteriösen Konzepten und den rätselhaften Ausdrucksweisen des Hl. Bonifaz und des Hl. Adhelme verstieg.

Im Übrigen war es zu einer plötzlichen Dekomposition der französischen Sprache gekommen. [...] In der französischen Sprache gab es keine Zeiträume, keinerlei Abfolgen von Zeitaltern mehr; der schattierte und superbe Stil der Goncourt und der abgehangene Stil eines Verlaine oder eines Mallarmé begegneten sich in Paris tagtäglich und lebten dort nebeneinander zum selben Zeitpunkt, in derselben Epoche, im selben Jahrhundert. ${ }^{12}$

Diese Vision hat etwas Faszinierendes und zugleich Erstickendes. Denn dies ist die Literatur einer Endzeit, eine Literatur, die in gewisser Weise zur höchsten Stufe möglicher Verdichtung vorgerückt ist und daran letztlich krepieren wird; und einer Literatur, deren Dekadenz innerhalb kurzer Zeit kam und zugleich eingebunden ist in ein System der Gleichzeitigkeit des Ungleichzeitigen, sind doch die Entwicklungslinien nicht mehr linear und gebündelt, sondern verlaufen gleichsam individuell und dispers. Dergestalt können wir in Paris zugleich die literarischen Formen des Aufblühens und der Dekadenz Seite an Seite erleben. Dies sind Gedanken und mehr noch Programmatiken, wie sie sieben oder acht Jahrzehnte später in der westlichen Postmoderne erneut und wesentlich stärker entstanden und eine veränderte Sicht der Zeit und der Zeiten anzeigten, Vorstellungen, welche auf einer trivialen und kommerziellen Ebene in ein Anything goes abdrifteten. Denn in der Gleichzeitigkeit des Ungleichzeitigen ist alles zugleich verfügbar und gestaltbar.

Dennoch ist es insgesamt eine Literatur, die früher oder später auf dem Totenbett der Geschichte ihren letzten Stoßseufzer ausstoßen und ihren letzten Atemzug tun wird. Dieser wird wie ein letzter großer Höhepunkt der Kunst sein; und doch ist diese Literatur der Vergangenheit überantwortet, wird - zumindest in den Augen von des Esseintes - bald schon unwiederbringlich historisch geworden sein. Welche Zukunft hat eine solche Kunst aber dann noch?

Eine derartige Kunst ist letztlich wie des Esseintes selbst: Letzter Spross einer langen Genealogie, an deren Anfang die starken, die robusten, die großen Geschlechter standen, die noch ein letztes Mal im letzten Nachkommen in einer raffinierten, destillierten, verdichteten Weise zum Ausdruck kommen und menschliche Gestalt annehmen, bevor sie auf immer verschwinden. Zugleich dürfen wir diese Ebene mit einer zweiten Ebene in Verbindung bringen: jener des Lesens, der Lektüre und damit auch der Leserfiguren. Denn des Esseintes repräsentiert einen neuen Lesertypus, der aktiv in die von ihm gelesenen Werke

12 Huysmans, Joris-Karl: A rebours, S. 261f. 
eingreift und sie sozusagen dekadentisiert, sie verdichtet und in die exquisitesten Düfte auflöst. Es ist hier nicht im Sinne des weit späteren Roland Barthes die Rede vom Tod des Autors, aber sehr wohl die Rede von einer Neudefinition der Rolle des Lesepublikums: einer Geburt des Lesers aus der Erschöpfung der Literatur.

In diesen Denk- und Schreibzusammenhängen ist die Notice, die uns die Geschichte von des Esseintes einblendete, als eine Art Roman in Kurzform zu verstehen, so wie wir auch in diesem Kapitel wesentlich mehr als die Panoramasicht der Literaturentwicklung des 19. Jahrhunderts erblicken dürfen. In der Tat versucht der Text, die Poetik von des Esseintes, die gleichwohl utopische Vision und philologische Expertise in einem bleibt, annähernd zu verwirklichen, ja literarisch-künstlerisch ins Werk zu setzen.

So ist auch er getragen vom Gefühl der Spätzeit und Höhe, zugleich aber auch des Umkippens in eine neue Phase, die sich mit den beiden Heiligen andeutet, welche gleichsam aus grauer Spät-Vorzeit nun in chronologischer Umkehrung an die Destillationen eines Baudelaire, Verlaine oder Mallarmé treten. Die Literatur, so scheint es, ist an diesem Punkt wirklich an ihr höchstes Ende gekommen; und sie wird an dieser Stelle vor allem und in erster Linie zu einer Kunst des Lesens, des Lesepublikums, das in seinem Innenraum, dem musée imaginaire seiner Bibliothek, eine innere Welt des Lesens sich entfalten lässt, die gleichsam am Ende aller Zeiten - und damit vor dem Jüngsten Gericht - steht. Wir treten vor dieses Tribunal wie einst Jean-Jacques Rousseau mit dem Buch in der Hand.

Doch nähern wir uns den Schlussakkorden von Huysmans' A rebours! Denn bislang haben wir eine Kunst noch nicht oder kaum gehört, die doch gerade in einem solchen Roman zu erwarten gewesen wäre: die Musik. Und das Erleben dieser Kunst - de la musique, avant toute chose, wie es in der Art poétique Paul Verlaines heißt - wird auch brav nachgeholt, wenngleich sie die letzte der abgehandelten Künste darstellt und vielleicht am widerstrebendsten gedeutet wird.

Denn des Esseintes ist auf diesem Gebiet nicht besonders begabt und bewandert. Sicher, er hat die Kunde von Berlioz vernommen und bewundert bestimmte Fragmente seiner Werke, traut sich aber aufgrund der Menschenmassen nicht in eine seiner Aufführungen! Natürlich ist er von der Idee des Gesamtkunstwerks bei einem Richard Wagner und davon, dass man nicht ein einziges Element aus seinem Zusammenhang herausbrechen dürfe tief beeindruckt! Doch sind die Werke Wagners jenen Franzosen, die nicht nach Bayreuth zum Festspielhügel pilgern, nur schwer zugänglich, da ihnen der französische Patriotismus die Opern- und Konzertsäle verschließe. Und Richard Wagner, wie in Marcel Prousts 
A la recherche du temps perdu, mittels telefonischer Übertragung zuhause, im eigenen Innenraum, zu genießen, ist in Huysmans' Zeiten leider noch nicht möglich.

Leichter ist es da schon mit Schumann und vor allem Schubert, dessen Lieder des Esseintes gefangen nehmen und bisweilen die fiebrige Erhitzung seines Gehirns musikalisch begleiten. Doch diejenige Musik, die ihn vielleicht am stärksten beeindruckt, ist vor dem Hintergrund seiner katholisch-jesuitischen Erziehung der gregorianische Gesang, jene Form der Musik, die wie ein Schrei der im Elend lebenden Menschheit zu ihrem Erlöser und Retter gedeutet wird. Es wäre daher schön, wenn Sie im Geiste, zusätzlich zu den Ausführungen in dieser Vorlesung, ein wenig gregorianische Musik im Kopfe hätten! Klar ist, dass es auch diese Musik ist, die den Ton anschlägt zum Ende des Romans, das wir ja bereits kennen, mithin den Bogen schlägt zu jenem Schrei des Esseintes', der nun - vor der erzwungenen Rückkehr nach Paris und nach dem Verlassen seines preziösen Refugiums - all seine Hoffnungen den Katholizismus richtet und verzweifelt ersehnt, an Gott, den christlichen Gott, glauben zu können.

Die beiden letzten Kapitel sind durchsetzt mit Bemerkungen und Beobachtungen zur Pathologie der Décadents. Ein allwissender Arzt, der mit mancherlei Neurosen, von denen man eigentlich wenig wisse, bei den gens du monde viel Erfolg habe, eine Figur, die gleichsam archetypisch jene von Sigmund Freud vorwegnimmt, erscheint - etwas mystisch gesprochen - als Seelenführer, der den letzten Spross einer großen Adelsfamilie aus der Verderbtheit einer zu exquisiten Sinnenwelt wieder herausführt in jene banalen Zerstreuungen, mit denen des Esseintes freilich nichts mehr anfangen zu können glaubt. Denn alles ist in dieser Welt am Ende zugrunde gegangen, ein letztes Mal aufglimmend und dann für immer verlöschend.

Soll er, ein Dandy und Angehöriger des alten Adels, der noblesse d'épée, etwa wieder in seinen Faubourg Saint-Germain zurückkehren, in dem der Adel seine kulturelle Führungsstellung und seine Macht auch in politischen Dingen längst verloren hat? Marcel Proust wird die lange Geschichte der Verschmelzung zwischen Adel und Großbürgertum in jenem Stadtviertel des Adels in seiner Recherche in epischer Breite erzählen. Bei Joris-Karl Huysmans ist diese gesellschaftliche und kulturelle Entwicklung bereits in kurzen Zügen angedeutet.

Selbst die katholische Kirche ist bereits vom Kapitalismus - der hier nicht so genannt wird, sondern als „Geist des Handels“ erscheint - angefressen, müssen die kirchlichen Klöster doch längst Rezepte und Rezepturen, Liköre und andere Wunderdinge verkaufen, um überhaupt überleben zu können. Wir ahnen schon: Am Schluss dieses Romans findet sich die Abrechnung mit dem vorrückenden 
Bürgertum und eine allgemeine Kulturkritik des sich seinem Ende nähernden Jahrhunderts.

Wir wollen an dieser Stelle - trotz der auch nicht uninteressanten medizinischen Schilderung des Falles von des Esseintes, die der zeitgenössisch sich so rasch entwickelnden Psychologie viel verdankt - doch nicht vergessen, diese Kulturkritik zur Kenntnis zu nehmen und in unsere allgemeinen Überlegungen zum Fin de siécle einzubeziehen. Betrachten wir also ein letztes Mal den Roman A rebours von Joris-Karl Huysmans und folgen den Gedankengängen seines Protagonisten des Esseintes!

Nach dem Geburtsadel war es also nun der Geldadel; es herrschte das Kalifat der Handelshäuser, der Despotismus der Rue du Sentier, die Tyrannei des Kommerzes mit ihren käuflichen und engen Vorstellungen, mit ihren eitlen und betrügerischen Instinkten.

Verbrecherischer und niederträchtiger noch als der entmachtete Adel oder der gefallene Klerus, stahl das Bürgertum beiden ihre frivole Zurschaustellung, ihre hinfällige Großsprecherei, welche es durch seinen fehlenden Lebensstil verhunzte [...].

So wurde die große Strafkolonie von Amerika auf unseren Kontinent verfrachtet; die unermessliche, die tiefgreifende, die inkommensurable Flegelei des Financiers und des Parvenüs kamen hinzu und erstrahlten einer ekelhaften Sonne gleich, über der götzenverehrenden Stadt, die, platt auf dem Bauche liegend, unreine Gesänge im Angesicht des gottlosen Tabernakels der Banken ejakulierte!

Los! Brich doch zusammen, Gesellschaft! Krepiere endlich, alte Welt!, brach es aus des Esseintes heraus, angewidert von der Schande des von ihm entworfenen Schauspiels [...]. ${ }^{13}$

Welch eine Dramaturgie in der Darstellung einer gesellschaftlichen, kulturellen und ökonomischen Entwicklung, die der letzte Adelsspross im Geiste des Kapitalismus einer triumphierenden Bourgeoisie in der ihn umgebenden Gesellschaft heraufziehen sah! An dieser Stelle wird der Kreis geschlossen und jenes veränderte Milieu sichtbar, in dem sich die neue Gesellschaft entwickelt, und in dem auch die Künste den ihnen zugewiesenen Ort finden müssen. Es ist eine Welt, die von den Banken und Financiers, den Bürgern, Kaufleuten und Händlern beherrscht wird.

Diese neue Welt ist eine Welt, die für des Esseintes den Stempel Amerikas trägt, den Stempel der Vereinigten Staaten von Amerika wohlgemerkt, die spätestens nach ihrer politischen Unabhängigkeit und ihrer erfolgreichen Revolution in Frankreich seit Alexis de Tocqueville und seiner Schrift über die Demokratie in den USA als Hort bürgerlicher Zukunft und Totengräber der zum Untergang verurteilten Welt, des alten Kontinents und der verfeinerten Kulturen Europas, gelten.

13 Huysmans, Joris-Karl: A rebours, S. $287 \mathrm{f}$. 
Diese neue Welt im Zeichen Amerikas ist aber für den Liebhaber aller möglichen kulturellen Verfeinerungen eine einzige Zwangsvorstellung, eine Dystopie.

So erscheint hier - wie in den etwas späteren Texten von Anatole France, freilich noch nicht von der Erfahrung der Niederlage von 1898 geprägt, in welcher Spanien und die romanisch geprägten Länder Lateinamerikas vor den vorrückenden und siegreichen Angelsachsen der USA auf die Knie gezwungen wurden das Spektakel einer neuen Macht der Kaufleute und Händler, die kein künstlerisches Raffinement mehr kennen, die nur eine platte Welt zu schaffen in der Lage sind. Sie leben und feiern unter einer banalen Sonne, bringen allerhöchstens noch ein unreines Ejakulieren über einer verderbten Stadt hervor, welche ihre Würde, ihre Kultur, all ihr Menschliches und Menschenwürdiges längst verloren hat. Was für ein Sittengemälde, Jahrzehnte noch vor dem Zusammenbruch der Alten Welt im Wahnsinn des Ersten Weltkrieges, der Grande Guerre!

Die Dekadenz von des Esseintes trifft also nicht notwendigerweise die ganze Gesellschaft. Sie betrifft vielmehr ein altes Frankreich, das sich seiner lateinischen Kulturtraditionen noch erinnert, das aber nun aufgesogen wird in einen neuen Taumel, dessen Zentrum nicht mehr notwendigerweise in der Alten Welt liegt, einer Welt, für die nunmehr Amerika zum Inbegriff und zur aktuellen Verkörperung aller Wunschträume des Kommerzes geworden ist. Stellvertretend hierfür sind nicht zuletzt auch die angelsächsischen Frauen, die - so ihr Portrait im Roman - zwar keineswegs als künstlerisch und kulturell sehr hochstehend, dafür aber als putzmunter und grundgesund dargestellt werden. Ihre körperliche Fitness überspielt alle Register kultureller Verfeinerungen, wie sie den französischen Dandy auszeichnen.

Als eine Passage, in der diese ganze Entwicklung zusammenfließt, mag jene eher nebensächliche Szene mit den femmes gaillardes angelsächsischer Prägung gelten, die beim Warten auf den Zug nach London nicht nur ohne Männer im Restaurant speisen gehen, sondern auch mit ihren kräftigen Zähnen ins Fleisch ihrer Beefsteaks beißen, die Kraft des Tierischen inkorporierend, die des Esseintes höchstens noch in Form von Fleischbrühe als Essenz (oder als Zitat) zu sich nehmen kann. So ist das Ende zugleich auch Anfang, freilich ein Anfang in einem Neuen, das von der alten Welt, von der alten Kultur, radikal abgelehnt und verachtet wird. Die altweltlichen Traditionslinien der Lektüre, aber auch der Liebe, scheinen zerschnitten und zerrissen.

Längst hat etwas Anderes die Herrschaft übernommen, etwas, das im Zeichen eines um unablässige Modernisierung bemühten Kapitalismus steht, im Zeichen der Krämer und Kaufleute, der Börsen und Banken. Aber sind die Literaturen damit am Ende? Nein, so dürfen wir aus heutiger Perspektive sagen! Das Ende der Literatur, das Ende der Literaturen der Welt wurde schon oft verkündet - zum 
letzten Mal vor nicht allzu langer Zeit in den geisteswissenschaftlichen Departments US-amerikanischer Universitäten. Doch um die Literatur und die Lektüre, um das Lesen und die Liebe muss uns wirklich nicht bange sein! Joris-Karl Huysmans' A rebours hat die Literatur an einen Grenzpunkt geführt, an welchem die Liebe und das Erotische, an welchem die Lektüre und das Lesen, kurz: an dem das Leben in all seiner Diversität und Vielverflochtenheit in neuem Glanz erscheint. Unsere Vorlesung geht selbstverständlich weiter. 